\title{
Fragility-Based Improvement of System Seismic Performance for Long-Span Suspension Bridges
}

\author{
Guanya Lu $\mathbb{D}^{1},{ }^{1}$ Kehai Wang $\mathbb{D}^{1,2}$ and Wenhua Qiu ${ }^{1}$ \\ ${ }^{1}$ School of Transportation, Southeast University, Nanjing 210096, China \\ ${ }^{2}$ Research Institute of Highway, Ministry of Transport, Beijing 100088, China \\ Correspondence should be addressed to Kehai Wang; kh.wang@rioh.cn
}

Received 31 January 2020; Revised 7 June 2020; Accepted 27 August 2020; Published 10 September 2020

Academic Editor: Antonio Formisano

Copyright (c) 2020 Guanya Lu et al. This is an open access article distributed under the Creative Commons Attribution License, which permits unrestricted use, distribution, and reproduction in any medium, provided the original work is properly cited.

In this study, a procedure is developed to evaluate and improve the seismic performance of long-span suspension bridges based on the performance objectives under the fragility function framework. A common type of suspension bridge in China was utilized in the proposed procedure, considering its approach structures according to earthquake damage experience and fortification criteria. Component-level fragility curves were derived by probabilistic seismic demand models (PSDMs) using a set of nonlinear time-history analyses that incorporated the related uncertainties such as earthquake motions and structural properties. In addition, one step that was covered was to pinpoint the capacity limit states of critical components including bearings, pylons, and columns. The stepwise improved seismic designs were proposed in terms of the component fragility results of the as-built design. Results of the comparison of improved designs showed that the retrofit measure of the suspension span should be selected based on two attributes, i.e., displacement and force, and the restraint system of the approach bridges was a key factor affecting the reasonable damage sequence. Necessarily, from the comparison of different system vulnerability models, the mean values of earthquake intensity of system-level fragility function developed by the composite damage state indices were used to assess the overall seismic performance of the suspension bridge. The results showed that compared to the absolutely serial and serial-parallel assumptions, the defined composite damage indices incorporating the thought of component classification and structural relative importance between the main bridge and approach structures were necessary and were able to derive a good indicator of seismic performance assessment, hence validating the point that the different damage states were dominated by the seismic demands of different structures for the retrofitted bridges.

\section{Introduction}

Long-span suspension bridges serve as the highly important transportation links during their service lives, and there are no expectations for these bridges to be retired in the foreseeable future. One of the greatest challenges of structural design can be attributed to the large displacements, low damping, and complex vibration modes resulting from the strong vibrations caused by earthquakes, wind, and traffic loadings. However, the seismic performances of such bridges must be of great concern, particularly in high-intensity earthquake regions.

In the past studies related to suspension bridges, researchers were mainly concerned about the vibrational characteristics and dynamic analysis of suspension bridges involving the use of the finite element method [1] and continuum approach [2], which were the bases of the seismic analysis. Although the performance-based seismic evaluation framework has been widely applied to structural engineering and conventional highway bridges, only a small number of studies have investigated the seismic performance of suspension bridges by employing the performance-based evaluation methods. Arzoumanidis et al. [3] set the seismic performance objectives of the new Tacoma Narrows Bridge and validated the design through the extensive analysis including the demand analysis of global structure and the capacity analysis of components. In addition, in order to account for the uncertainties of certain factors related to the ground motion input, Sgambi et al. [4] conducted a seismic analysis of long-span suspension bridges through the Monte Carlo simulations. The mean 
value and variance of displacements and stresses were used to describe the seismic responses of structures. Karmakar et al. [5] studied the seismic performance of the Vincent Thomas suspension bridge retrofitted with viscoelastic dampers and obtained the ductility demands of towers in terms of fragility probability. However, the studies mentioned above solely considered the component-level fragilities and focused on the damage of the towers. Additionally, it must be noted that the approach span of the San Francisco-Oakland Bay Bridge had fallen-off during an earthquake event, which caused the closure of transportation link [6]. Therefore, it can be concluded that leaving out the effect on approach structures may skew the results in the system seismic evaluation of long-span bridges. Due to the difference and connection in structural dynamic behavior and design strategy between the suspension span and approach structures, the optimization of system seismic performance and a reasonable indicator that can reflect the overall seismic performance for long-span bridges will be appealing.

Previous studies have indicated that fragility functions are effective tools by which to assess the damaging potential of small-to-medium-span highway bridges under earthquakes. Fragility functions can connect the given damage states with earthquake intensity. Both component-level and system-level fragilities have been developed for a class of bridges in a certain region, such as Central America $[7,8]$, California, USA [9], Turkey [10], Greece [11], and Italy [12]. Barnawi and Dyke [13] and Zhong et al. [14, 15] evaluated the seismic fragility of a cable-stayed bridge and compared different retrofit measures using fragility techniques. Although their studies noted the necessity of derivation of system-level fragility of piers (towers) and bearings, a serial connection was used in estimating the system fragility. The key point of their methods depends on a relatively conservative way to quantify correlations between critical components. One is full correlation, while the other is partial correlation obtained from joint probabilistic seismic demand models [8]. It is worth discussing whether it is reasonable to apply these correlations to the fragility development of overall long-span bridge system. In addition, the application of fragility curves has been proficient for comparing and selecting retrofit measures and isolation strategies for conventional highway bridges [16-18].

In the context of the aforesaid review, the key purposes of this study are to develop a procedure of the performance-based seismic assessment for long-span suspension bridges, and to examine the applicability of the proposed indicator for evaluating the overall bridge system seismic performance. A typical long-span suspension bridge in China was selected. A series of detailed finite element models were built using OpenSEES [19] software that can perform nonlinear time-history analysis. The procedure incorporated the uncertainties of ground motions and structural properties. The backbone of the proposed procedure is fragility-based improvement of seismic performance for long-span suspension bridges, including the definition of engineering demand parameters (EDPs) and the capacity limit state thresholds associated with the case-dependent components. Component fragility is used to pinpoint the vulnerable components of the overall bridge under earthquakes and served as the basis of stepwise retrofit strategies. The retrofit candidates are determined by earthquake damage experiences, related component seismic experiments, and expert opinions. Finally, the indicators appropriate for characterizing the seismic performance of overall system for long-span suspension bridges are proposed and discussed. Finally, the effectiveness of the suggested index in the system seismic performance evaluation is further identified by comparing the indicators of the retrofitted designs with those of the as-built design.

\section{Procedure Description}

This study used PSDM generated by cloud approach and capacity limit state models based on multiperformance objectives to develop the fragility curves of bridge components rooted in the response data obtained from a set of nonlinear time-history analyses. The seismic fragility could be defined as the conditional probability of a structure seismic demand $S_{d}$ reaching or exceeding its capacity $S_{c}$ at a given earthquake intensity measure (IM), which could be expressed as follows:

$$
\text { Fragility }=P\left(S_{d} \geq S_{c} \mid \mathrm{IM}\right) \text {. }
$$

It is well known that the PSDM built by cloud approach is based on three assumptions: (1) lognormal distribution of seismic demand and structural capacity; (2) constant dispersion assumption for all IM ranges; and (3) a power model between seismic demand and IM. Therefore, the conditional probability under a given IM can be written as follows:

$$
P\left(S_{d} \geq S_{c} \mid \mathrm{IM}\right)=1-\Phi\left(\frac{\ln \left(S_{c}\right)-\ln \left(a \mathrm{IM}^{b}\right)}{\sqrt{\beta_{\mathrm{d} \mid \mathrm{IM}}^{2}+\beta_{c}^{2}}}\right),
$$

where $S_{d}$ is the mean value of seismic demand conditioned on an IM; $S_{c}$ is the limit state threshold of structure corresponding to each defined damage state (DS); $\beta_{d \mid \mathrm{IM}}$ and $\beta_{c}$ indicate the dispersion values of demand and capacity, respectively; and $\Phi(\cdot)$ is the standard normal cumulative distribution function. Both $a$ and $b$ are regression coefficients, which can linearly regress in log-transformed spaces.

The dispersion of seismic demand $\beta_{d \mid \mathrm{IM}}$ can be estimated as follows:

$$
\beta_{d \mid \mathrm{IM}}=\sqrt{\frac{\sum\left(\left(\ln \left(d_{i}\right)\right)-(\ln a+b \ln (\mathrm{IM}))\right)^{2}}{N-2}},
$$

where $d_{i}$ is the $i$ th demand value obtained from the analytical samples, and $N$ denotes the sample sizes.

The definitions of PSDM and capacity limit states are imperative in the formation of component fragility curves. Component fragility curves facilitate to highlight the weak links in the overall bridge system and develop the retrofit and repair decisions. However, if the comprehensive seismic evaluation of complicated structures with multicomponents is conducted, then the correlations of various components must be considered. According to the objective of this study, the highlights of the proposed procedure are outlined as follows:

(1) The propagation of uncertainties is beneficial to the reflection of their statistical significance, which include 
the ground motions that meet the site conditions, representing a broad range of intensities and various modeling parameters such as material strength, structural properties, and damping ratio. The general practice is taking the uncertainty sources as random variables to form $N$ finite element models of suspension bridges in the as-built design using a Latin hypercube sampling (LHS) technique, and then pair these models with a set of $N$ ground motions in order to carry out a series of nonlinear time-history analyses.

(2) The final step to derive bridge component fragility curves is to pinpoint the vulnerable components based on the recorded peak response data in nonlinear time-history analyses, by which to define their corresponding limit state thresholds at various damage states. In addition, the application of optimal IM is also the key link to ensure the reliability of the seismic vulnerability assessment.

(3) The component-level fragility curves are calculated using equation (2). For the purpose of reducing the various damage potential of critical bridge components in the initial design, different seismic designs are proposed based on earthquake damage experiences, related component seismic experiments, and expert opinions. Next, the effectiveness of seismic measures is evaluated using the critical component-level fragility.

(4) The optimum structural seismic performance is selected in this study, taking the bridge system-level fragility as the objective function according to the definition of damage states and fragility results of various components obtained from steps 2 and 3 . Considering the vulnerability degree of each component and postearthquake repair cost, it is helpful to evaluate the seismic performance of the bridge system by combining the critical components in a reasonable manner. For suspension bridges, cable systems and pylons are primary load-carrying components, and pylons can be only allowed to be of limited damage. The damage of bearings can be allowed to compensate by the effective seismic measures. For approach bridges with the small-tomedium spans, the postearthquake serviceability of bridges depends on the damage stage of columns, abutments, and bearings. A popular seismic design of this type of bridges is fusing actions of bearings as force-limiting connections to reduce the damage of substructures. A bridge structure consists of multiple members with the same function, but in various locations. The working principle of pylons and columns is similar to that of the series system, due to the fact that the damage or collapse of one of the pylons or columns will directly affect the postearthquake availability of the bridge system. The multiple bearings form a parallel system to jointly support superstructures, and a single damage has less influence on the overall bridge system. Earth pressures on abutments are further increased as a result of the pounding between the deck and abutment backwall for the seat abutments, which leads to an increase in the abutment deformation. However, the difficulty of repairing abutments is relatively small, and the effect on emergency traffic is slight. A parallel system can also be adopted to simulate an abutment system. For a global bridge structure, once any type of component system is damaged, it will have a significant impact on the overall bridge system. The overall bridge system is close to the series combination of different component systems, which can be called a bridge system based on the series-parallel system.

Zhong et al. [14] summarized the method of component classification appropriate for long-span bridges and held that the components of long-span bridges can be classified as primary, secondary, and accessory based on the relative importance of load-carrying capacity and repairing costs. Therefore, the application of a serial assumption between component systems may bias the seismic fragility assessment of the bridge system. Zhang and Huo [18] assigned a weighting ratio of 0.75 and 0.25 to columns and bearings, respectively, for ordinary highway bridges in USA and proposed the composite damage state for the bridge system. The repair-related strategy variables including repair cost and time are considered based on the direct and indirect economic losses that are caused by the damage of bridge components. The damage to primary and secondary components at any level will account for a majority of repair cost, including repairing most components and a long closure of traffic. The replacement costs of accessory components primarily rest on their extensive damage including reinstallation of bearings and restoration of girder that might be resulted from pounding and unseating, which interrupts traffic at a short time. Combined with the reality of bridge construction in China and the repair-related variables of the critical components incorporated in the bridge system, this study separately proposes the composite damage state indices of the long-span and conventional bridge system as follows:

$$
\begin{aligned}
\mathrm{DS}_{\text {main bridge }}= \begin{cases}\operatorname{round}\left(0.85 \cdot \mathrm{DS}_{\text {pylon }}+0.15 \cdot \mathrm{DS}_{\text {bearing }}\right), & \mathrm{DS}_{\text {bearing }}<\text { Extensive, } \\
\operatorname{round}\left(0.75 \cdot \mathrm{DS}_{\text {pylon }}+0.25 \cdot \mathrm{DS}_{\text {bearing }}\right), & \text { other, }\end{cases} \\
\mathrm{DS}_{\text {approach bridge }}= \begin{cases}\operatorname{round}\left(0.7 \cdot \mathrm{DS}_{\text {column }}+0.2 \cdot \mathrm{DS}_{\text {abutment }}+0.1 \cdot \mathrm{DS}_{\text {bearing }}\right), & \text { other, } \\
\operatorname{round}\left(0.75 \cdot \mathrm{DS}_{\text {column }}+0.25 \cdot \mathrm{DS}_{\text {bearing }}\right), & \mathrm{DS}_{\text {column }} \text { or } \mathrm{DS}_{\text {bearing }}=\text { Extensive, } \\
4, & \mathrm{DS}_{\text {column }} \text { or } \mathrm{DS}_{\text {bearing }}=\text { Collapse. }\end{cases}
\end{aligned}
$$


It should be noted that the aforementioned development of damage indices for the bridge system is only for a single bridge system and is closely related to the definition of damage states of the components. For long-span suspension bridges composed of a main bridge and several approach bridges, a reasonable and comprehensive seismic vulnerability evaluation is of great significance to the construction of project and postearthquake repairing cost. A bridge system with the similar structural properties could be regarded as a series system. However, the differences in structural importance and repairing costs cannot be neglected because of the structural differences between the long-span bridges and small-to-medium-span bridges. The weighting ratios of $a$ and $(1-a)$ are assigned to the main bridge system and approach bridge system, respectively, which have the ability to capture the contributions of the main bridge and approach bridges to the vulnerability of the overall bridge system. Therefore, the rational range of system fragility could be accurately determined as follows:

$$
\mathrm{DS}_{\text {system }}=\operatorname{round}\left[a \cdot \mathrm{DS}_{\text {main bridge }}+(1-a) \cdot \mathrm{DS}_{\text {approach bridge }}\right] \text {, }
$$

where the round-off principle can be used for the "round".

The composite damage state in equations (4) and (5) can be incorporated in the PSDM when the correlation between concerned components with the use of covariance matrix is known. In this case, Monte Carlo simulation is used to compare the demands obtained from the joint probabilistic seismic demand models [8] and multidimensional component capacities in the $M\left(=10^{5}\right)$ random samples at a range of the IM values. The basic principle of developing fragility curves for the long-span suspension bridge system is shown in Figure 1.

\section{Case Study}

3.1. Bridge Description and Simulation. This study selected the Taoyuan Bridge spanning the Jinsha River as the study case. The bridge is characterized by the geometric and mechanical features of a suspension bridge, which is the most common type of bridge construction in China. The bridge has a total length of $731 \mathrm{~m}$ and consists of a singlespan simply supported suspension bridge measuring $636 \mathrm{~m}$ and a continuous steel box-girder approach bridge with three spans measuring $30 \mathrm{~m}, 35 \mathrm{~m}$, and $30 \mathrm{~m}$, respectively. The longitudinal elevation of the bridge is illustrated in Figure 2.

The main bridge has a thin-wall steel girder along the longitudinal direction, with an overall width of $31 \mathrm{~m}$ from curb to curb and a height of $3 \mathrm{~m}$, accommodating four lanes of traffic. The gate-type towers include two RC box-section legs with overall heights of $75 \mathrm{~m}$ and $70 \mathrm{~m}$ on its two sides, respectively. Also, there is one crossbeam installed along the height of pylons in order to enhance the lateral stiffness of structures. At the base, the tower legs are anchored to the 6 m-thick concrete footings. The pedestals for the placing bearings are designed between the concrete footings due to the shorter distance between the deck and tower base. The bored piles serving as the foundations of pylons and located at the leg of each tower have a diameter of $2.2 \mathrm{~m}$. The areas of each main cable and suspender are $0.1626 \mathrm{~m}^{2}$ and 0.001316 $\mathrm{m}^{2}$, respectively. Gravity anchorage has been applied to the main cable anchorage on both sides of the bridge. The approach bridges are divided into left and right bridges with the identical configurations on the north side. For each approach bridge, there is a three-span continuous steel boxgirder bridge with a pile-bent abutment, of which the middle span is supported by two double-column bents with integral pile-shaft. The width and depth of the superstructure are $12.75 \mathrm{~m}$ and $1.53 \mathrm{~m}$, respectively. The circular sections of columns with a diameter of $1.8 \mathrm{~m}$ have a height of $7 \mathrm{~m}$, and the cast-in-drilled-hole piles measure $1.9 \mathrm{~m}$ in diameter. The piles of abutment are provided by a circular section of $1.5 \mathrm{~m}$ in diameter, and the height of the backwall is $1.88 \mathrm{~m}$.

The description of this study's analytical modeling procedure is outlined using OpenSEES software [19] for the prototype bridge in the as-built design. A beam-column element with distributed plasticity fiber was used to model the pylons and columns, in order to account for the material nonlinearity. In addition, the axial force-moment interactions of pylons were captured in the model. Each fiber was simulated via a reasonable stress-strain relationship which was dependent on unconfined concrete, confined concrete defined by the Mander theoretical model, and longitudinal reinforcements that considered the Bauschinger effects, as illustrated in Figure 3. The corresponding mechanical indices, such as material strength, axial compression ratio (ACR), and reinforcement ratios of Sections I and II, all met the Chinese code requirements [20].

The main cable element was tension-only, which was modeled as a finite number of large-displacement truss elements using the Ernst method accounting for the sag effect [21]. Each suspender element was identical to the simulation of the main cable, but there was no sag effect. The initial stress of the cable system was also considered in the model, as shown in Figure 4(a). An elastic beam element was utilized to simulate the crossbeam of the pylons and stiffening girder, as well as the girders and cap beams of the approach bridges. The foundations were modeled by six spring elements, which indicated that, in the future, they are not expected to be damaged under earthquake shaking.

It should be noted that pot bearings were applied to the as-built design, which consequently became the significant factors in the overall responses and functionality of the approach bridges. The longitudinal response of sliding pot bearings detailed in Figure 4(b) was simulated using a bilinear element [20]. The full-scale experiments of Steelman et al. [22] found that properly proportioned steel for fixed pot bearings can achieve a reliable dry friction response between the bearing component and superstructure or substructure after the rupture of the anchor bolt. Correspondingly, the behavior of fixed pot bearings was modeled as shown in Figure 4(c). The fixed pot bearings were designed to be located at the C2 column, as shown in Figure 1. Finally, the pounding stiffness between the adjacent decks (Figure $4(\mathrm{~d})$ ) was estimated by the sum of their axial stiffnesses [23]. 


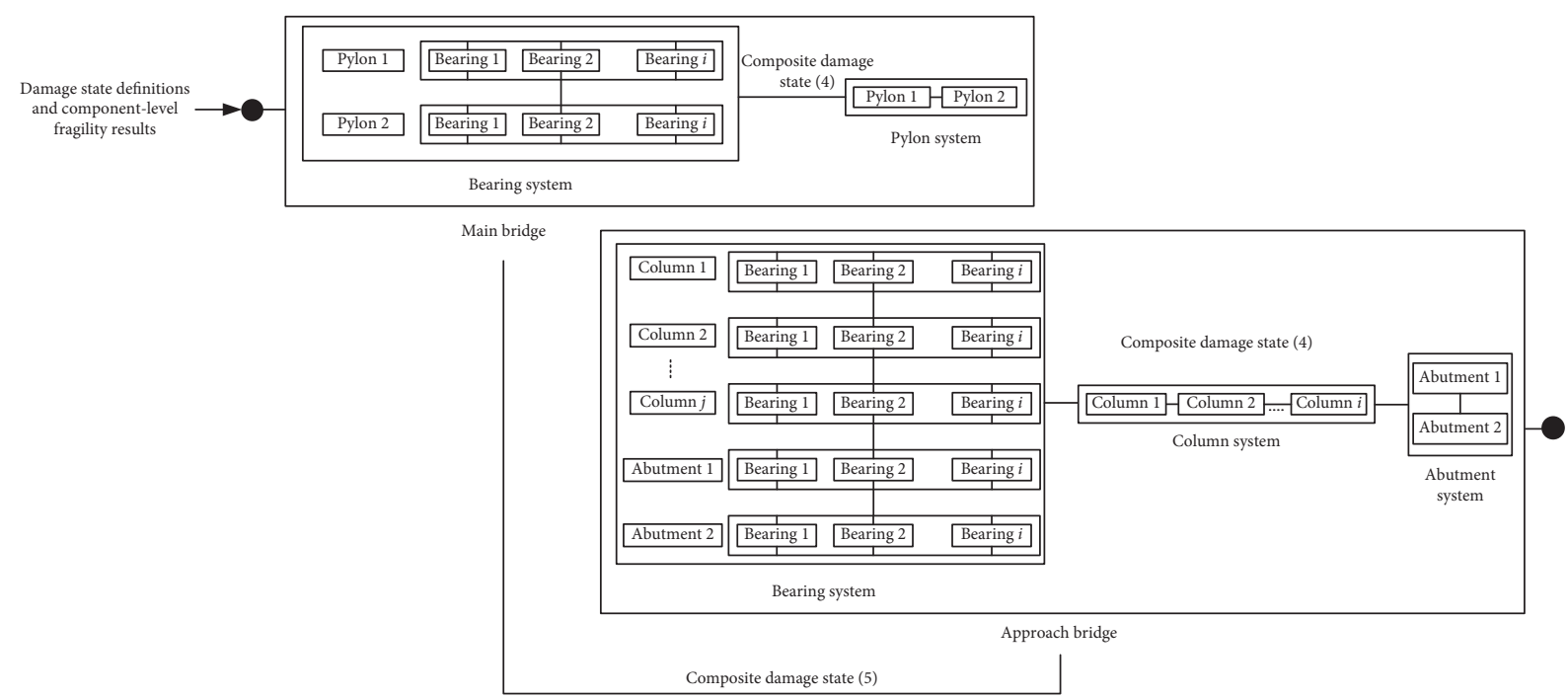

FIgURE 1: Bridge system based on the series-parallel system and composite damage state.

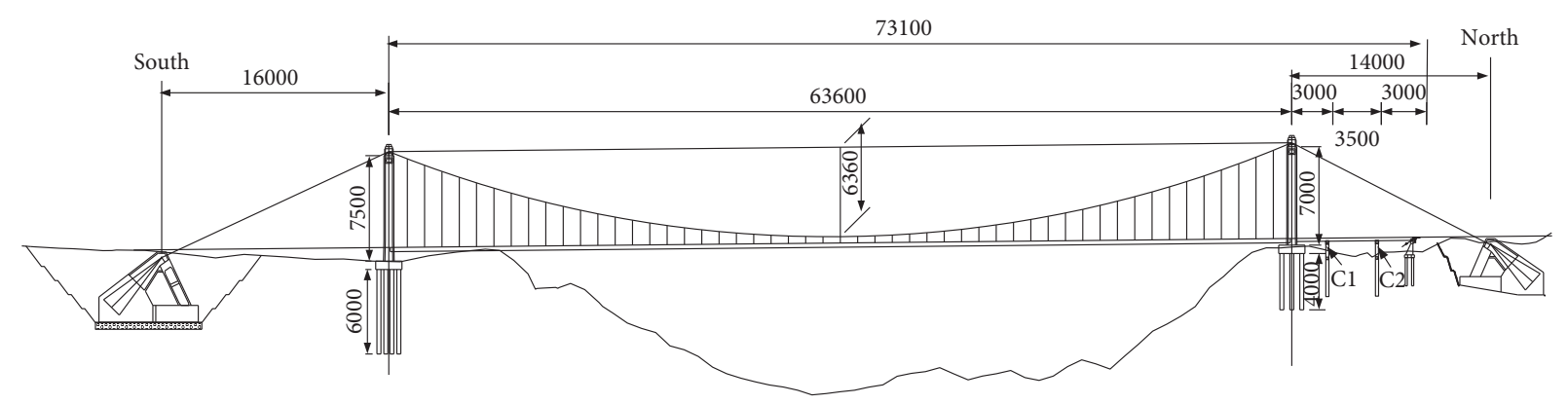

Figure 2: Configuration of the Taoyuan Suspension Bridge $(\mathrm{cm})$.

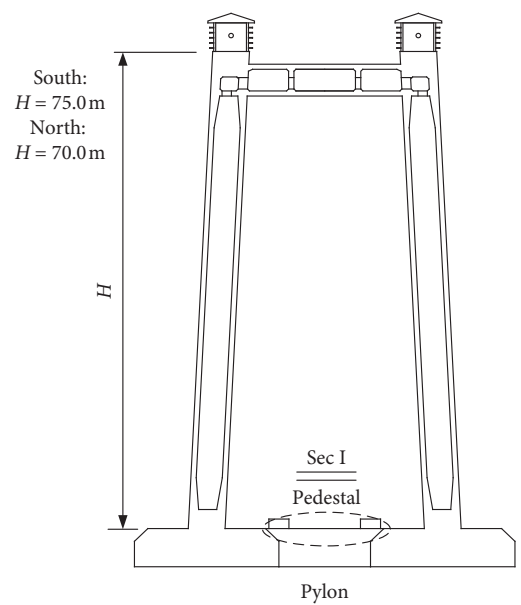

(a)

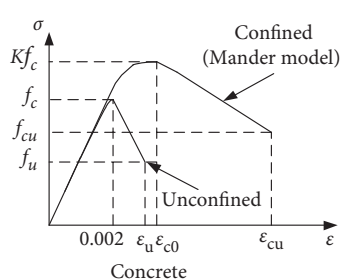

(b)

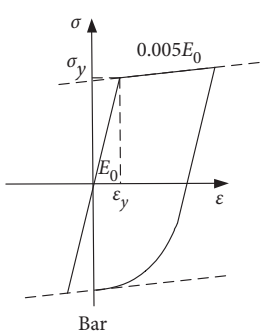

(c)

FIgUre 3: Continued. 


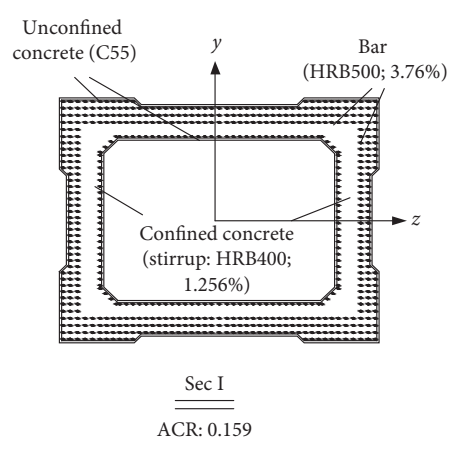

(d)

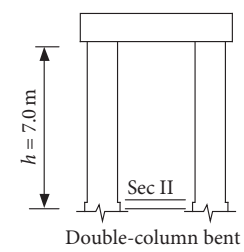

(e)

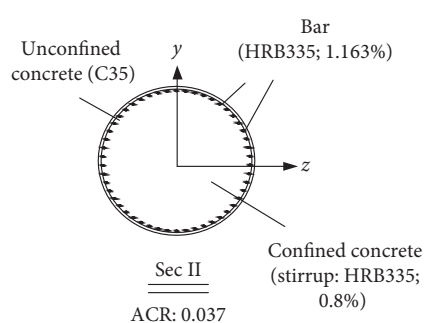

(f)

Figure 3: Sketch and material model of the pylons and bents of the examined suspension bridge.

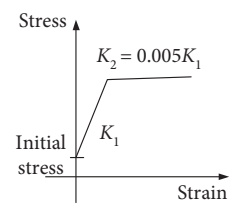

(a)

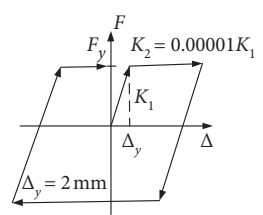

(b)

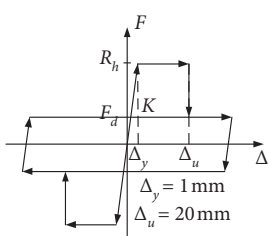

(c)

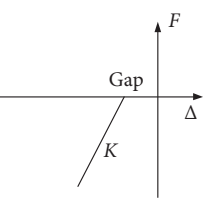

(d)

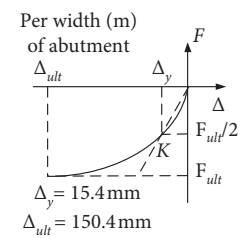

(e)

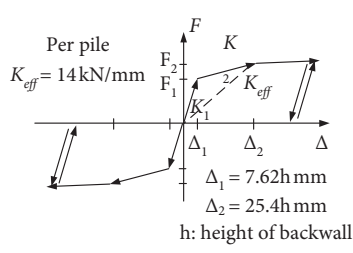

(f)

Figure 4: Constitutive relations of the various components: (a) cable and suspender; (b) sliding pot bearing; (c) fixed pot bearing; (d) pounding; (e) abutment backfill; (f) abutment pile.

The shear keys contribute to the constraint of transverse movement between the girder and pier. $\mathrm{Xu}$ and $\mathrm{Li}$ [24] proposed a modified model based on the structural properties of shear keys in China, which was used to build the force-displacement relation of shear keys by separating the contributions of steel and concrete in parallel as shown in Figure 5. The critical parameters of the shear keys can be calculated using Xu's method according to the actual design, which represents the yield $\left(\Delta_{1 Y}\right)$, nominal $\left(\Delta_{1 n}\right)$, degraded $\left(\Delta_{1 d}\right)$, and ultimate $\left(\Delta_{1 u}\right)$ deformations, respectively. The simulation can accurately reflect the mechanical behavior of the shear keys.

The seat type abutment is shown in Figure 6. The longitudinal resistance to seismic forces is provided jointly by the passive action of the backfill soil and active action of the piles [25]. Meanwhile, the transverse response is resisted by the piles. The passive and active responses of abutments were simulated using hyperbolic soil material [26] and trilinear force-displacement relationship, respectively, which were connected in parallel to capture the abutment responses. In addition, the pounding effect between the deck and abutment was simulated using a linear model without energy dissipation. The stiffness of pounding spring between the superstructure and abutment was proposed to be ten times that of the backfill soil stiffness [27].

3.2. Uncertainty Treatment in the FE Model. The LHS approach is usually used to account for the uncertainties in fragility analysis, such as structural geometry, material strength, component properties, deck mass, and damping in the modeling, which is considered to be a variance reduction sampling technique. It is noted that the uncertainty of structural geometry is not taken into account in this study for the development of bridge-specific fragility curves. In the foregoing approach, the probability distributions were assumed for each parameter, and each random variable was divided into the several equal intervals which correspond to $5 \%$ to $95 \%$ of the cumulative probability. The considering modeling parameters and their probability distributions are presented in Table 1. Statistically significant yet nominally identical 3D bridges were built using the LHS, so as to account for the abovementioned uncertainties, then the bridges were paired randomly with the selected ground motions.

3.3. Ground Motion Input and Intensity Measure. The necessity to carry out a large number of nonlinear time-history analyses depends on a significant number of earthquake records selected for the PSDM. In this study, a data set of 80 recorded ground motions and 20 Los Angeles-pertinent unscaled ground motions were extracted from the PEER strong motion database and the SAC project database, respectively [29]. These ground motions can represent the characteristics of the bridge site. They were placed into five magnitude-distance bins for the purpose of covering the rational and broad ground motion intensity. The first four bins included combinations of low and high magnitudes, and large and small fault distances. The magnitudes varied between 5.7 and 7.0 while the fault distances ranged from 13.0 to $60.0 \mathrm{~km}$. The characteristic of the ground motions in 


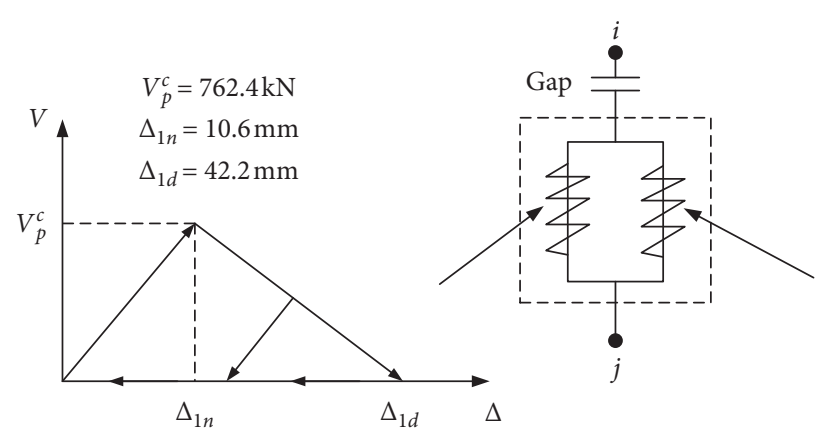

Hysteretic property of concrete

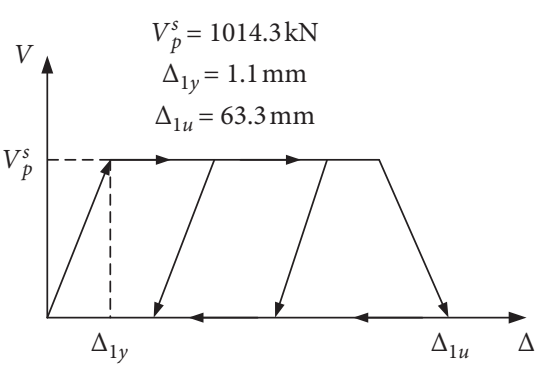

Hysteretic property of steel

Figure 5: Analytical model of shear keys.
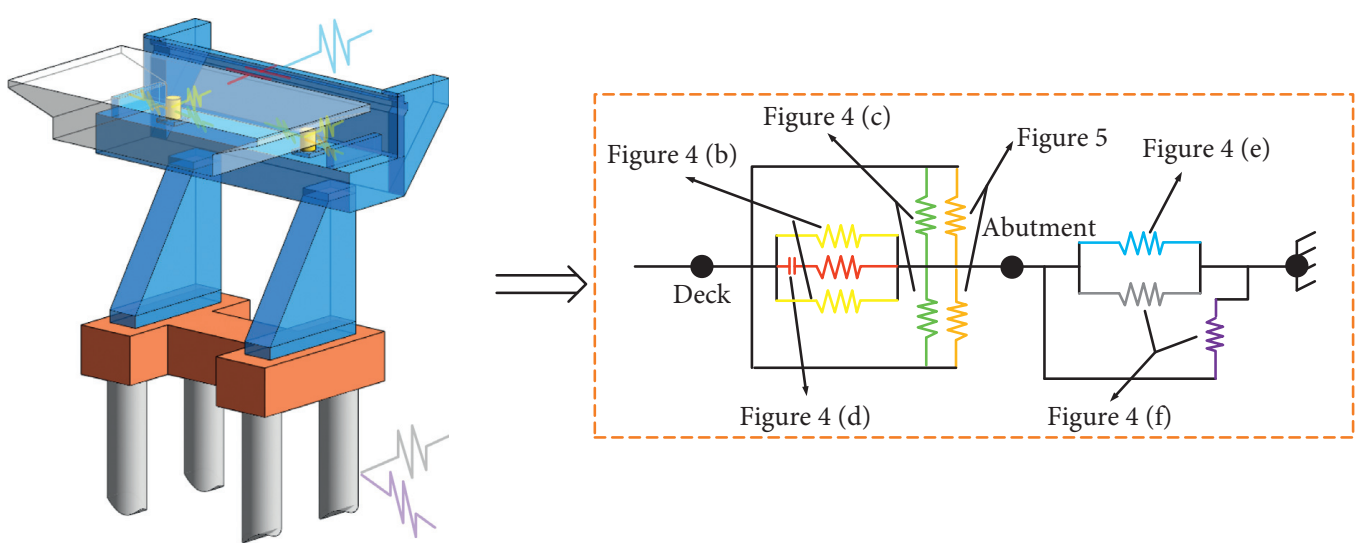

FIgURE 6: Pile-bent abutment simulations.

TABLE 1: Uncertainty parameters incorporated in the modeling design.

\begin{tabular}{|c|c|c|c|c|c|c|}
\hline \multicolumn{2}{|c|}{ Modeling parameter } & Probability distribution & Mean & $\mathrm{COV}$ & Unit & Source \\
\hline \multirow{2}{*}{ Concrete compressive strength } & C55 & \multirow{2}{*}{ Normal } & 46.6 & 0.149 & \multirow{2}{*}{$\mathrm{MPa}$} & \\
\hline & C35 & & 32.1 & 0.164 & & \\
\hline \multirow{3}{*}{ Steel yield strength } & HRB500 & \multirow{3}{*}{ Lognormal } & 569.6 & & \multirow{3}{*}{$\mathrm{MPa}$} & {$[20]$} \\
\hline & HRB400 & & 455.7 & 0.0743 & & \\
\hline & HRB335 & & 381.6 & & & \\
\hline \multirow{2}{*}{ Friction coefficient } & Sliding pot bearing & Uniform & 0.03 & 0.33 & - & {$[14]$} \\
\hline & Fixed pot bearing & Lognormal & 0.2 & 0.002 & - & [7] \\
\hline \multirow{2}{*}{ Abutment } & Passive stiffness & Uniform & 20.15 & 0.25 & $\mathrm{kN} / \mathrm{mm} / \mathrm{m}$ & {$[7]$} \\
\hline & Active stiffness & Uniform & 14.0 & 0.29 & $\mathrm{kN} / \mathrm{mm} /$ pile & [9] \\
\hline \multirow{3}{*}{ Gap } & Deck-deck & \multirow{2}{*}{ Normal } & 760 & 0.2 & \multirow{2}{*}{$\mathrm{mm}$} & [7] \\
\hline & Deck-abutment & & 80 & & & \\
\hline & Deck-shear key & Uniform & 120 & 0.29 & $\mathrm{~mm}$ & [16] \\
\hline Damping ratio & & Uniform & 1 & 0.1 & - & [7] \\
\hline Deck mass & & Normal & 0.02 & 0.15 & - & [28] \\
\hline
\end{tabular}

COV: coefficient of variation.

the fifth bin was that the fault distance was less than $15 \mathrm{~km}$. The ground motions were given in two orthogonal components, and the acceleration values adopted were computed as the geometric mean values $\left(S_{a}=\sqrt{S_{a L} \cdot S_{a T}}\right)$. The peak ground acceleration ranged from $0.043 \mathrm{~g}$ to $1.12 \mathrm{~g}$. Figure 7 shows the distributions of peak ground accelerations (PGA); peak ground velocities (PGV); earthquake magnitudes $(M)$; and fault distances $(R)$ of 100 ground motion records, as well as the acceleration spectra with a damping ratio of 0.02 . The two orthogonal components of the selected earthquake records were randomly input along the longitudinal and transverse directions of the bridge.

PGA, PGV, PGD, spectral acceleration, or Arias Intensity of earthquake can be selected as the IM candidates, which are used to characterize earthquake intensity. The linear relations with the interesting EDPs from probabilistic 


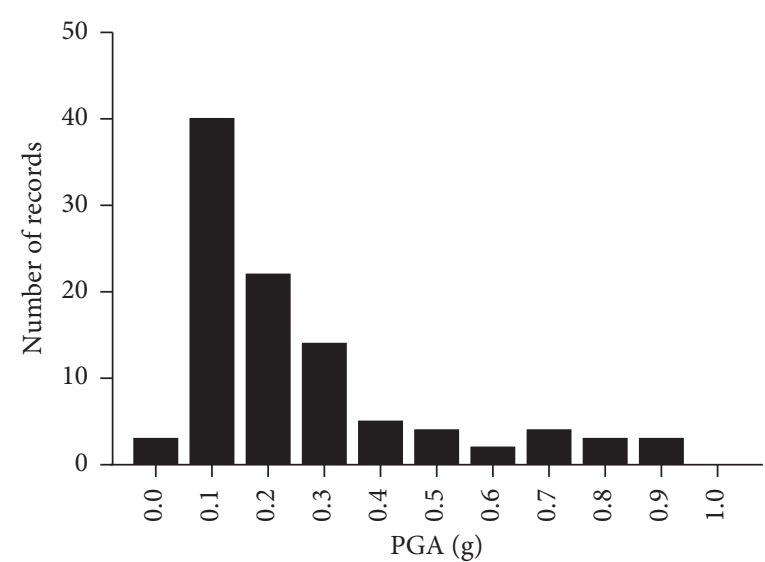

(a)

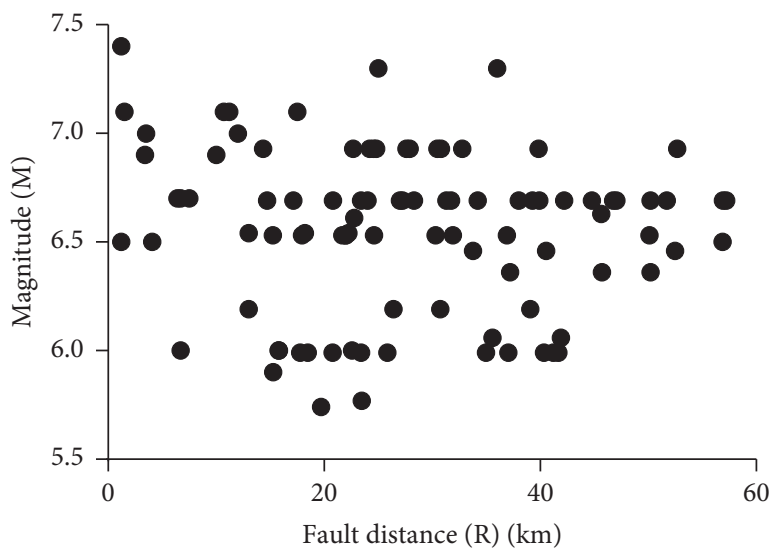

(c)

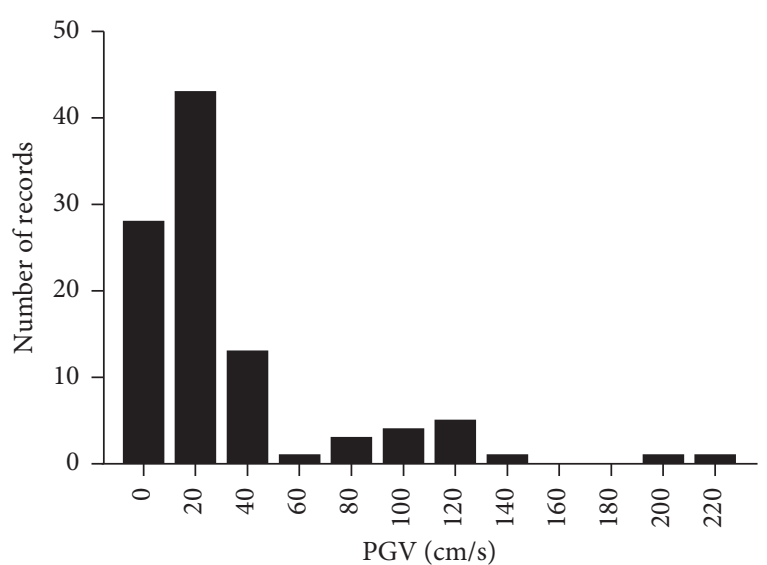

(b)

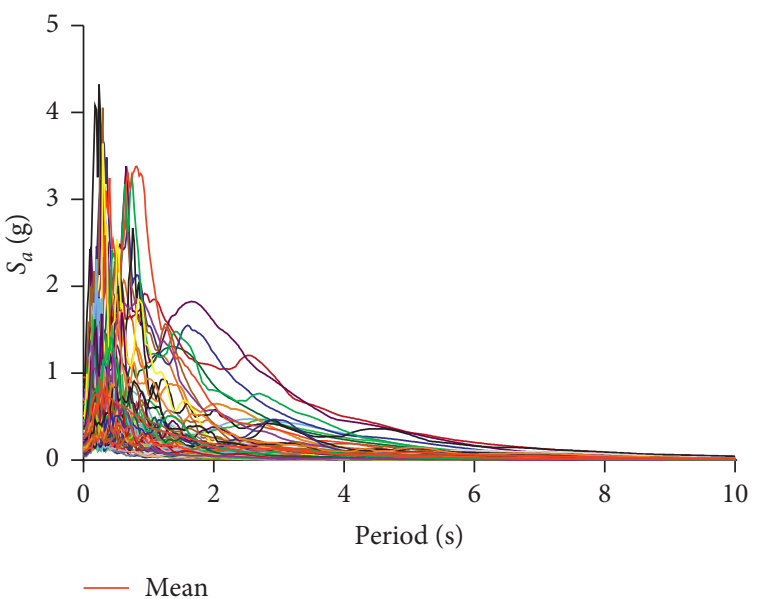

(d)

FIgure 7: Characteristics of the selected ground motions: (a) PGA; (b) PGV; (c) M and R; (d) acceleration response spectra.

seismic demand analysis in the logarithmic reference frame can be adopted to determine the optimal IM. In the previous studies, PGA and spectral acceleration were selected as the optimal IMs for highway bridges $[9,30]$ when applying the multiple measures containing efficiency, practicality, proficiency, and sufficiency. Mackie et al. [31] suggested both PGA and PGV are good choices of IM in related to the EDP measures in highway overpass bridges. Zhong et al. [14] pointed out that PGA and PGV are the most efficient, practical, and proficient IMs for long-span cable-stayed bridges, yet PGV tends to be the optimal IM in terms of sufficiency. Therefore, PGV can be utilized as the IM in this study.

3.4. Engineering Demand Parameters. The peak demands of critical components are adopted as EDPs for the development of PSDMs and the choice of optimal IM. Table 2 lists the critical EDPs for the examined bridge, which have been considered in the fragility evaluation of the suspension bridge.

3.5. Capacity Limit State Models. In the present study, a capacity model was used to measure component damage, which was described by a damage index as a function of the selected EDPs. These models are usually discrete and characterized by the onset of various damage states based on the experimental data. Similarly, the uncertainties of capacity models are also expressed by median $S_{c}$ and dispersion $\beta_{c}$. The definition of damage states must be matched with postearthquake bridge functionality and repair strategies in the bridge seismic fragility assessments. Foundations, decks, and anchorages are typically identified as nondamaged components in the simulations. The damage state values of bearings were determined, so as to compare with two factors including the pounding gaps between the adjacent components and seating width, which can reflect the possible pounding and unseating as shown in Figure 8, in addition to the damages to bearings themselves, that is, the deformation capacity of the bearings. Table 3 lists the slight (DS1), moderate (DS2), extensive (DS3), and collapsed (DS4) damage states defined in the initial design for pot bearings at various locations based on their allowable deformation and structural dimensions.

The columns of conventional highway bridges are often forced into the state of nonlinearity under strong earthquakes, of which the criteria of damage states were studied $[8,9,16]$. It is found that there are major differences in 
TABLE 2: The critical EDPs for the examined bridge.

\begin{tabular}{|c|c|c|}
\hline Engineering demand parameters & Abbreviation & Direction \\
\hline Curvature ductility of pylon cross-section (south, north) & PCD@(S, N) & Longitudinal and transverse \\
\hline Displacement of bearings of the main bridge & MBD & Longitudinal and transverse \\
\hline e relative to yield value of main cables & MAF & - \\
\hline $\mathrm{d}$ value of su & SAF & - \\
\hline columns $(\mathrm{C} 1, \mathrm{C} 2)$ & CCD@(C1, C2) & Longitudinal and transverse \\
\hline at column $(\mathrm{C})$ and abutr & ABD@(C, A) & Longitudinal and transverse \\
\hline Deformation of backfill passive pressure at abutment & BPD@A & Longitudinal \\
\hline nt & $\mathrm{PD}$ & Longitudinal and transverse \\
\hline $\mathrm{De}$ & EJD@(D, & Longitudinal \\
\hline Deformation of shear key at columns (C) and at abutments (A) & SKD@(C, A) & Transverse \\
\hline
\end{tabular}

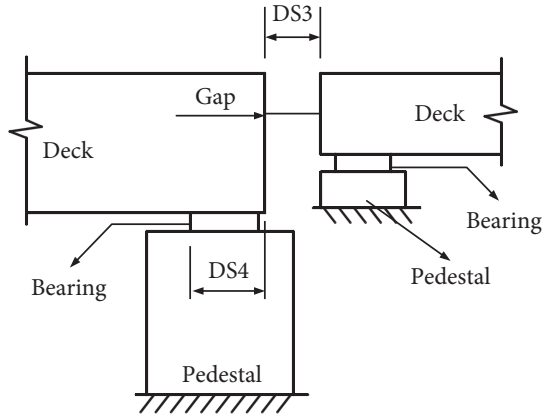

(a)

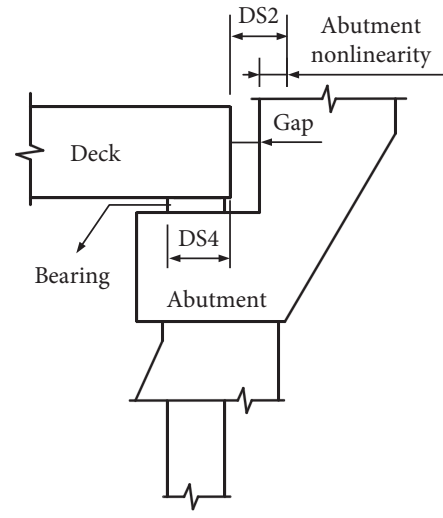

(b)

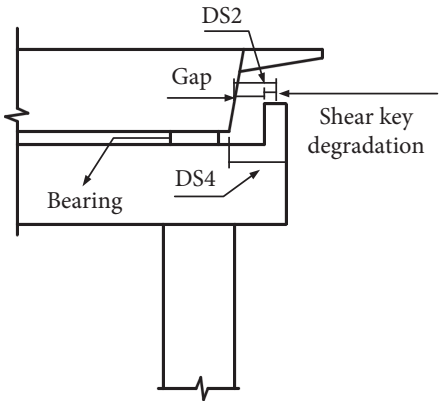

(c)

FiguRE 8: Damage control and unseating prevention damage states for bearing displacement: (a) between decks; (b) between deck and abutment; (c) between deck and shear key.

TABLE 3: Limit state thresholds for pot bearings (m).

\begin{tabular}{lcccc}
\hline & DS1 & DS2 & DS3 & DS4 \\
\hline Criteria & $\begin{array}{c}\text { Allowable slipping } \\
\text { displacements }\end{array}$ & $\begin{array}{c}\text { Spherical skateboard radius, } \\
\text { body separation of bearings }\end{array}$ & $\begin{array}{c}\text { Possible pounding between } \\
\text { adjacent decks or deck and pylon }\end{array}$ & Possible unseating \\
MBD/L & 0.25 & 0.31 & 0.76 & 1.555 \\
MBD/T & 0.02 & 0.31 & 0.45 & - \\
Criteria & Allowable slipping & Possible pounding, entering of abutments & Spherical skateboard radius, & Possible unseating \\
ABD@C/L & displacements & nonlinearity or shear key degradation & body separation of bearings & 0.775 \\
ABD@C/T & 0.02 & 0.095 & 0.28 & 0.57 \\
ABD@A/L & 0.02 & 0.1622 & 0.20 & 0.775 \\
ABD@A/T & 0.05 & 0.095 & 0.20 & 0.87 \\
\hline
\end{tabular}

geometric sizes, material strengths, and ACR of sections between the pylons of suspension bridges and columns of conventional highway bridges. Therefore, it is necessary to develop a modal pushover analysis to define the damage states of critical cross-sections of pylons. In the analytical processes of this study, the material strain and nonlinear moment-curvature relationship of critical cross-sections were characterized to measure the damage levels of the suspension bridge pylons.

First, the reasonable pylon models were required to be developed using fiber beam elements in longitudinal and transverse directions, as detailed in Figure 3. An elastic spring which was equivalent to the restraint of main cable was attached to the top of the pylon, taking into account the influence of the main cable stiffness in the longitudinal direction models. The determining process of the equivalent stiffness can be referred to in the Ernst formula and the results reported by Kiureghian and Sackman [21].

Second, as illustrated in Figure 9, the inertial force distributions were back-calculated from the multimode spectrum analysis using a 3D bridge model, as shown in equations (6)-(8), which included the contributions of high vibration modes and reflected the properties of inertial force distributions as follows: 


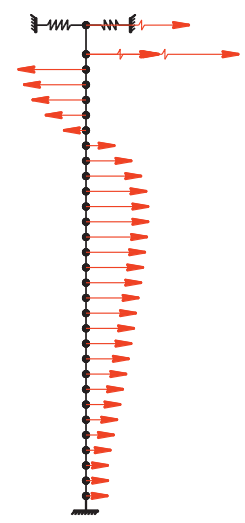

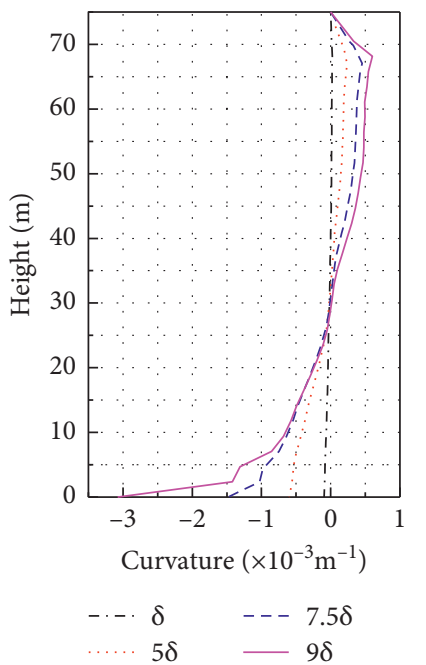

(a)
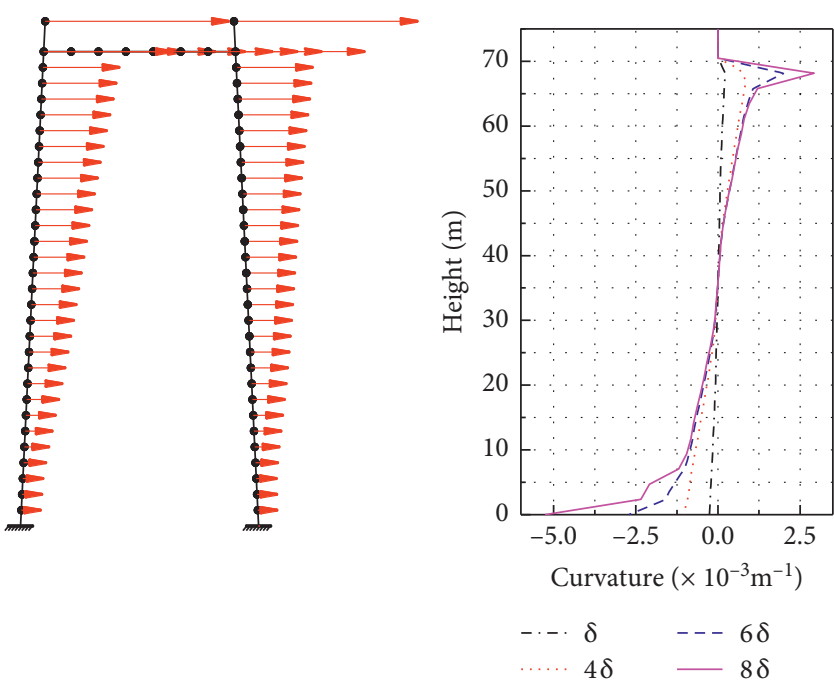

(b)

FIgURE 9: Inertial force and curvature distributions: (a) longitudinal; (b) transverse.

$$
\begin{gathered}
F_{i j}=S_{j} \gamma_{j} \phi_{i j} m_{i}, \\
Q_{i j}=\sum_{m=i}^{N} F_{m j} \\
Q_{i}=\sqrt{\sum_{j=1}^{N} Q_{i j}^{2}} \\
P_{i}=Q_{i}-Q_{i+1},
\end{gathered}
$$

where $S_{j}$ and $\gamma_{j}$ are the spectral acceleration and participation factor associated with the $j$ th mode, respectively; $F_{i j}, \varphi_{i j}$, and $Q_{i j}$ represent the seismic load, mode displacement, and shear force at the $i$-node associated with the $j$ th mode, respectively; $m_{i}, Q_{j}$, and $P_{i}$ indicate the mass, shear force, and inertial force at the $i$-node, respectively; and $N$ denotes the number of nodes.

Next, the inertial forces were loaded to the nodes of pylon models. Both the material and geometric nonlinearities were incorporated into the pushover analyses which were used to investigate the potential failure mechanisms and assess the ductility capacities of pylons.

The seismic designs of pylons can develop inelastic behaviors, which were controlled by the material strain limits. Figure 9 details the curvature distributions along the pylon heights with the increase of $\delta$, where $\delta$ was the loading displacement at the control point. It was observed that plastic hinge zones typically occur at the bases of pylons and above and below the horizontal crossbeams. Also, plastic hinges may progress to the intermediate height in the longitudinal direction. The development of plastic hinges at the bases of pylons can be much severer and also occur earlier than in other zones. Therefore, the curvatures at the bottoms of pylons may effectively provide measurements of the damages to pylons.

The mechanical indices of pylon cross-sections which correspond to the four damage state characteristics following the damages are detailed in Figure 10. The curvature ductility can be easily determined by the pushover analysis results, in addition to that of the DS2. The numerical data can be transformed to a bilinear curve that has a value of DS2 based on the equal energy rule per original curve. Similarly, another pushover analysis was applied to the double-column bend of the approach bridge based on the specifications [20]. The four limit state thresholds of the cross-sections at the bottom of pylon and columns in both the longitudinal and transverse directions are listed in $\mathrm{Ta}-$ ble 4 . It was observed that the seismic capacity of longitudinal direction was superior to that of transverse direction, and a good ductility capacity existed in both directions.

In the present study, the definitions of damage state thresholds of main cables and suspenders were dependent on the steel strand characteristics of the strength and deformation rates. A total of $85 \%$ of the ultimate strength (nominal yield strength) was conservatively acted as the failure index. Namely, the corresponding ratio of force to yield value was 1.0. It is a common viewpoint that the accidental loss of one suspender will not cause immediate failures of a bridge, with the exception of the loss of the main cables. Therefore, DS3 and DS4 were only defined based on the classification of suspenders and main cables, respectively. The corresponding elastic and ultimate deformation of abutments and shear keys were, respectively, specified the thresholds of DS1 and DS2 with the recommendations of Caltrans [25]. The damage of expansion joints only defined as the DS1, due to the lack of a higher-level damage model. This was objectively logical, since the joints can be replaced with the new once damaged, thereby suggesting the rationality for just one threshold of component damage. Table 5 summarizes the damage state thresholds of the abovementioned components.

The assignments of dispersions of capacity models of components appeared to be the most difficult tasks for the researchers. According to the previous research studies, 0.35 was adopted in the abutment and RC components, including 


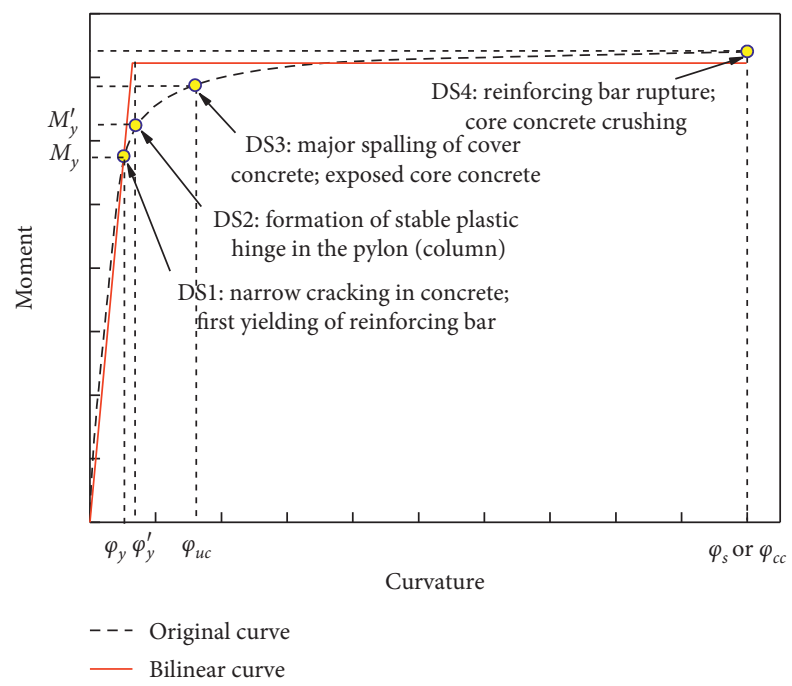

Figure 10: The damage state definitions of the pylon and column cross-sections.

TABLE 4: Limit state thresholds of pylon and column cross-sections.

\begin{tabular}{lcccccccc}
\hline & \multicolumn{2}{c}{ DS1 } & \multicolumn{2}{c}{ DS2 } & \multicolumn{2}{c}{ DS3 } & \multicolumn{2}{c}{ DS4 } \\
& Pylon & Column & Pylon & Column & Pylon & Column & Pylon & Column \\
\hline Longitudinal & 1.00 & 1.00 & 1.34 & 1.44 & 3.26 & 6.16 & 21.43 \\
Transverse & 1.00 & 1.00 & 1.27 & 1.31 & 3.09 & 4.32 & 25.64 \\
\hline
\end{tabular}

pylons and columns [9]. The COV of main cables and suspenders was 0.1 , taking the low variability of high strength steel strands into account [16]. The descriptive dispersions of the remaining components were calculated to be 0.25 for the two lower damage states (DS1 and DS2) and 0.47 for the higher damage states (DS3 and DS4) [8].

3.6. Assessment of Vulnerable Components. The component fragility curves were derived by steps 1-3 detailed in Section 2 to identify vulnerable components and regions, as shown in Figures 11 and 12. The pot bearings were shown to be the most vulnerable components for the main bridge, which inferred the complete damages to pot bearings themselves and reflected a higher probability of pounding between the adjacent decks and unseating in the longitudinal direction. The transverse responses of bearings did not cause obvious damage compared to the longitudinal responses. The pylons were the primary components for load carrying where inelastic material response could potentially occur. The transverse vulnerability was more obvious than the longitudinal vulnerability for the lower damage states. However, the probability of extensive damage was extremely low or even zero. With respect to the main cables and suspenders, the increases in their forces which could potentially occur during rare earthquakes were confined to about $15 \%$ (for the mean values) of the forces resulting from the dead loads, as illustrated in Figure 12, which also indicated that the maximum values of main cable stress had occurred at the saddles of pylons and in the side spans. The stress values of suspenders achieved the maximum at the middle and end. In summary, the cable system was found to be secured against damages in which the stress values were much lower than the yield values, even under strong earthquake shaking. It was noted that the large deflection and cable angle changes between the main span and side spans would lead to the strong shear in the longitudinal direction between the cables and saddles, and the slipping damages to the saddles at the top of the pylons during earthquakes were identified as high-risk.

For the approach bridges, the columns were determined to be the most fragile components in both the longitudinal and transverse directions. The application of the fixed pot bearings resulted in a large force and deformation of the columns, the complete damage of sliding pot bearings, and apparent pounding between the decks and abutments. These actions subsequently caused the inelastic responses of abutments, but the shear keys were protected from failure transversely. Although the ductility mechanism of approach bridges was designed, it was considered to be a defective seismic system with irrational sequences of component damage occurrences in high-seismicity regions.

\section{Improved Seismic Designs and Comprehensive Evaluation}

4.1. Improved Design of Main Bridge. As results shown in the evaluation of vulnerable components, a large deck displacement of the suspension span would occur during earthquakes, which caused pounding and even unseating 
TABLE 5: Limit state thresholds of cable system, abutment, shear key, and expansion joint.

\begin{tabular}{lcccccc}
\hline & & DS1 & DS2 & DS3 & DS4 & Unit \\
\hline \multirow{2}{*}{ Abutment } & Passive & 15.04 & 150.4 & - & - & $\mathrm{mm}$ \\
& Active/transverse & $7.62 \mathrm{~h}$ & $25.4 \mathrm{~h}$ & - & $\mathrm{mm}$ \\
\hline \multirow{2}{*}{ Shear key } & & 10.6 & 63.3 & & $\mathrm{~mm}$ \\
\multirow{2}{*}{ Expansion joint } & Deck-deck & 0.76 & - & - & - \\
& Deck-abutment & 0.08 & - & - & $\mathrm{m}$ \\
\hline
\end{tabular}
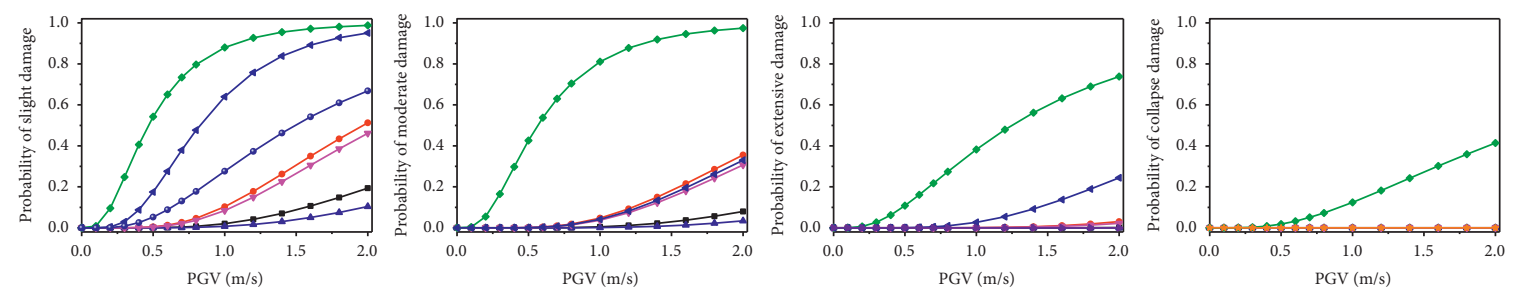

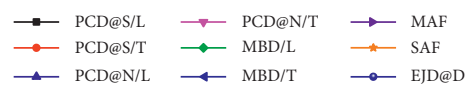

(a)
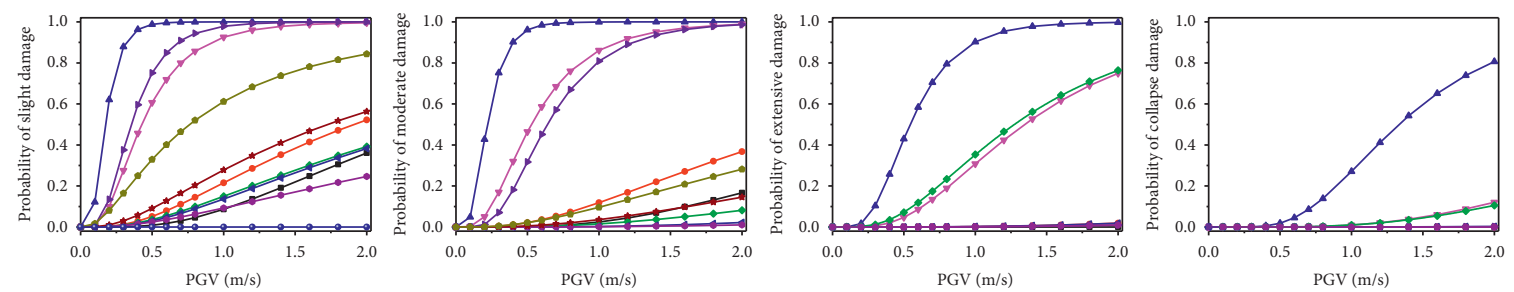

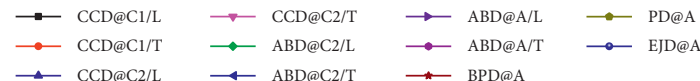

(b)

FIGURE 11: Component fragility curves for the suspension bridge: (a) main bridge; (b) approach bridge.
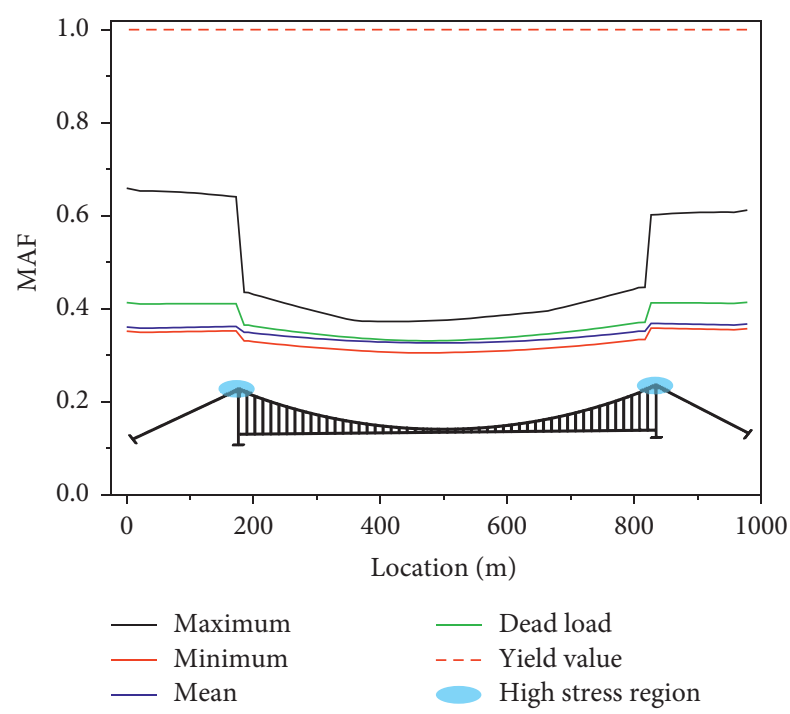

(a)

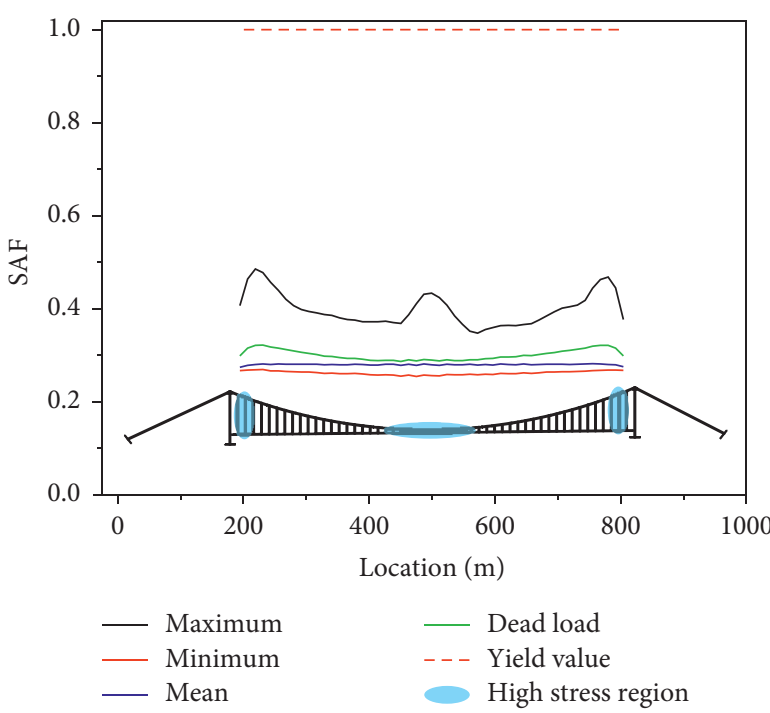

(b)

FIGURE 12: Force distributions of the (a) main cables and (b) suspenders. 
when there were no additional restraints in the longitudinal direction. Therefore, it was consistent to suggest that supplementary devices should be equipped to mitigate the deck movements to some extent. The reduction of deck or bearing displacements can be taken as the retrofitted objective for the suspension span. Fragility analyses were conducted on the retrofitted bridges that covered the general strategies as follows:

Case 1: the analysis model of the bridge used a fluid viscous damper equipped between the deck and each pedestal on both sides of the bridge.

Case 2: the analysis model of the bridge used an elastic cable installed between the deck and each pedestal on both sides of the bridge.

Case 3: the analysis model of the bridge used three pairs of flexible central buckles located in the middle section of the span.

The main bridge was assumed to have identical mechanical parameters at each location in various design schemes. The dampers and elastic cables were, respectively, modeled using zero-length elements with Maxwell and tension-only materials, and the flexible central buckles were simulated as the same as the suspenders elements in OpenSEES.

The experimental testing of fluid viscous dampers has shown that the force-velocity with fractional velocity power law relation can describe the suitable mechanical behavior:

$$
f_{D}=C_{D}|\dot{u}|^{\alpha} \operatorname{sgn}(\dot{u}) \text {, }
$$

where $\alpha$ is a real positive exponent of which value depends on the piston head orifice; $C_{D}$ is viscous damping coefficient, with units of force per velocity raised to the $\alpha$ power, $\mathrm{kN} \cdot(\mathrm{m} /$ s) ${ }_{\alpha} ; \dot{u}$ indicates the velocity of damper; and $\operatorname{sgn}(\cdot)$ is the signum function. Research by Li et al. [32] indicated that viscous damping coefficients range from $2500 \mathrm{kN}(\mathrm{m} / \mathrm{s}){ }_{-\alpha}$ to $5000 \mathrm{kN}(\mathrm{m} / \mathrm{s})_{-}{ }_{\alpha}$ and can be simulated with a uniform distribution. The velocity exponents can be assumed to vary uniformly from 0.3 to 0.5 .

The axial stiffness of elastic cables and flexible central buckles is regarded with the material, length, and crosssection area. It was assumed that the yield strength of steel strands of $f_{y}=1420 \mathrm{MPa}$ was the mean value and followed a lognormal distribution with a $\mathrm{COV}=0.1$. The stiffness values of single elastic cable based on past work employed a uniform distribution ranging from $1.25 \times 10^{5} \mathrm{kN} / \mathrm{m}$ to $2.5 \times 10^{5} \mathrm{kN} / \mathrm{m}$. In addition, the other mechanical properties such as length and area can be determined by the following relations:

$$
\begin{gathered}
L>\left(\frac{E \Delta}{f_{y}}\right), \\
k_{E}=\left(\frac{E A}{L}\right),
\end{gathered}
$$

where $L, E$, and $f_{y}$ are the length, Young's modulus, and yield stress of elastic cables, respectively and $\Delta$ represents the controlled deck displacement, which was available for $0.6 \mathrm{~m}$ in the examined bridge.

According to expert opinion, three pairs of flexible central buckles were the most common type of central buckle, of which the cross-section areas were the same as those of the suspenders.

Figures 13(a) and 13(b) illustrate bearing displacement distributions are formed for the three retrofit measures at the same ground motion intensity levels. The mechanical behaviors of measures strongly affect the effectiveness. It can be concluded that owing to the similar EDP distributions of dampers and elastic cables, the corresponding ground motion intensities were similar when generating the same pounding probability. The flexible central buckles were extremely susceptible to yielding failure, thereby causing low efficiency in the displacement restrictions. Therefore, pounding probabilities can be directly observed by conditioning on the median responses of dampers and elastic cables instead (Figure 13(c)). The control force produced by devices is another noteworthy consideration in retrofit design. The more force the devices require, the larger and more expensive they usually are [13]. To take both deformation and force into account, Figures 13(d) and 13(e) provide the contours of the pounding probability. The comparison showed that the damper deformations featured slightly larger slopes in the horizontal direction, yet the difference in effect on the deformations of the dampers and elastic cables was not significant for reducing the objective pounding probability. Conversely, damper force was less sensitive to the pounding probability than cable force. The elastic cable forces reached on average up to $e_{3.2}(\approx 24.5)$ times those of the damper under the same pounding probabilities. These findings implied that difficult anchorage challenges existed in the case of guaranteeing the efficiency of elastic cables, and the bridge decks possibly experienced higher stress. In addition, the difference in force was substantial when controlling the displacement, which showed that dampers can contribute additional damping and stiffness to the structural system, while elastic cables completely transferred the inertial forces. Therefore, the coordination and balance of displacements and forces should be simultaneously considered in the vibration mitigation of largespan bridges. In this study, the application of fluid viscous dampers was identified as the preferred retrofit in the longitudinal direction for the main bridge. The additional damping ratio provided by the fluid viscous dampers can be calculated by the following equation:

$$
\varepsilon=\frac{C_{D}}{2 m \omega_{\text {eff }}},
$$

where $C_{D}$ is damping coefficient of linear fluid dampers, $\mathrm{kN} \cdot(\mathrm{s} / \mathrm{m})$, which is equivalent to nonlinear dampers based on equal energy dissipation per hysteresis loop [17]; $\omega_{\text {eff }}$ is system natural frequency corresponding to the vibration along the axis of bridge; and $m$ is system mass. It was shown that an additional damping of $20.6 \%-31.8 \%$ can offer an effective controlling mechanism for the reduction of pounding between the adjacent decks. 


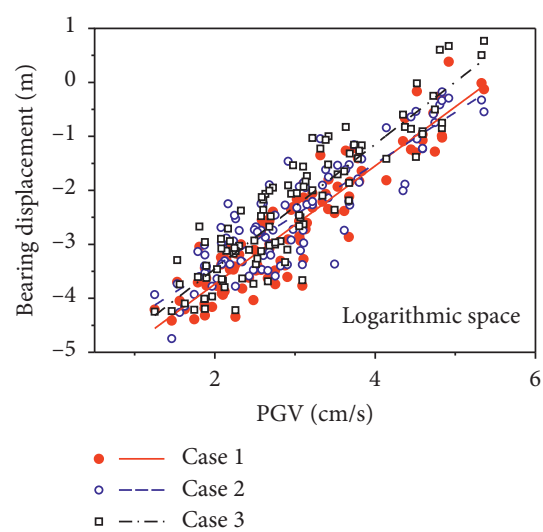

(a)

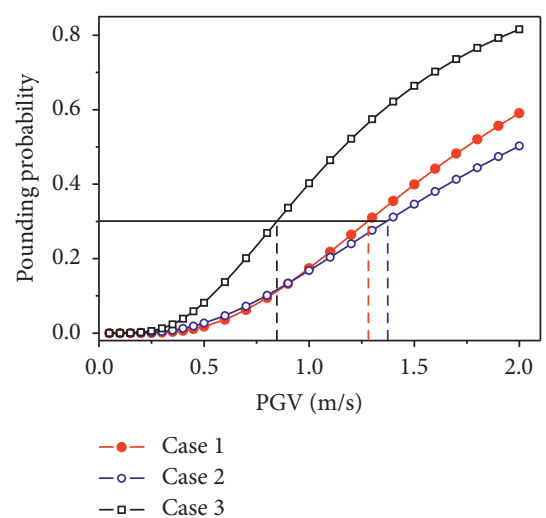

(b)

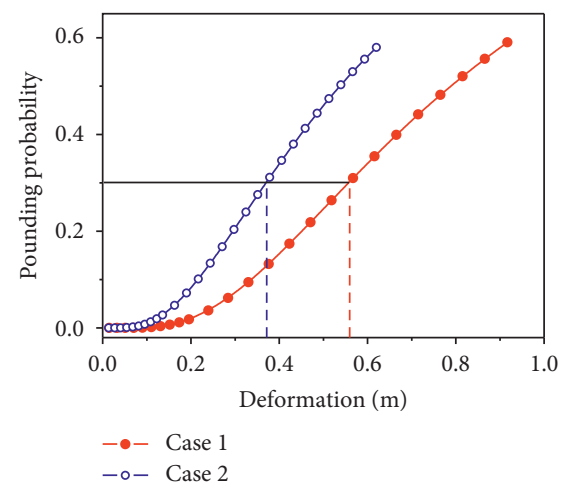

(c)

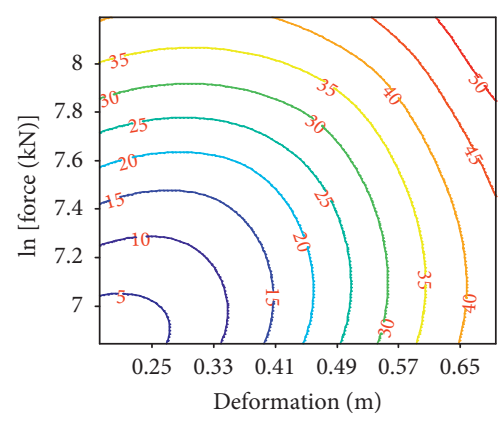

(d)

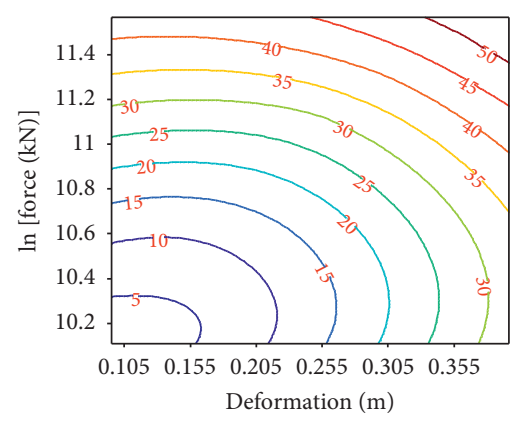

(e)

FIGURE 13: Choice of the three retrofit measures based on deformations and forces: (a) EDP-IM relation; (b) pounding probability conditioned on IM; (c) pounding probability conditioned on deformation; contours of pounding probability for (d) dampers and (e) elastic cables.

Figure 14 depicts the change of components vulnerabilities before and after the application of dampers. It can be observed that the retrofit measure played limited roles in the fragility reduction of the self-damaged bearings in long-span bridges. Since the additional longitudinal rigidity to girder was provided by the dampers, the transverse responses such as girder displacement and pylon curvature would increase as ground motion intensity increased. The influences on the cable system responses and the longitudinal responses of pylons were found to be negligible. Another phenomenon was that the longitudinal fragility of the abutments significantly decreased with the reduction in the pounding probabilities between the decks and abutments of the approach bridges. It was inferred that the pounding between the adjacent decks was likely to affect movement of the approach bridges and that the pounding effect would be transmitted along the girder.

4.2. Improved Design of Approach Bridges. The damage potential of each component for the approach bridges was high due to the high collapse risks posed by the usage of the fixed piers. The structural designs of small-to-medium-span highway bridges in China show the fact that the superstructures are usually placed onto laminated elastomeric bearings (LEBs), which tend to come into direct contact with the bridge girders and substructures without anchoring. The typical types of seismic damages of these bridges consisted of large girder movements, bearings sliding, failures of shear keys and expansion joints, and abutment cracking during the Wenchuan and Yushu earthquake events in China. Meanwhile, the bridge columns displayed relatively low damage ratios under earthquakes [33]. The design can be referred to as a quasi-isolation system, which is primarily realized by strategically employing bearings sliding as forcelimiting connections between girders and substructures. In addition, the isolation strategies of lead-rubber bearings (LRBs) are usually employed in the high-seismicity regions, which can be taken as a comparison of the quasi-isolation system. The two restraint systems consist of bearings, shear keys transversely located at the cap beams, and restrainer cables longitudinally anchored to the abutments (or pedestals). In order to calculate the seismic responses of the approach bridge, the related experiments were completed and summarized, and applied to the force-displacement relations of the restraint system components.

The detailed experiment of LEB consulted previous academic achievements [34]. An example is shown in Figure 15(a), where the feature points marked by rectangular and circular represented initial walking and obvious sliding responses, which illustrated that the mechanical property of bearings would degrade as the displacements increased after entering the friction sliding state until it remained nearly constant. When there was no specific test, the horizontal force $F_{d}$ in the stable friction stage can be $0.7 F_{\max }$, where $F_{\max }$ was the corresponding maximum static friction at the 


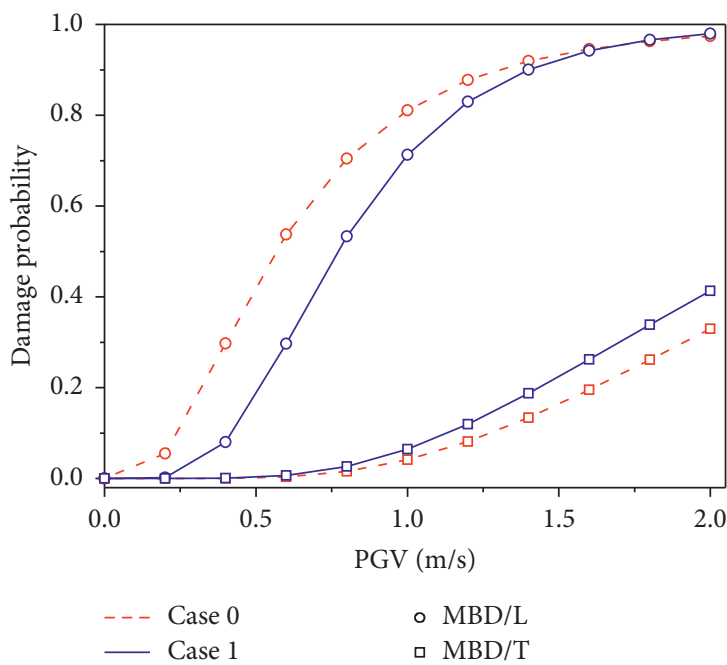

(a)

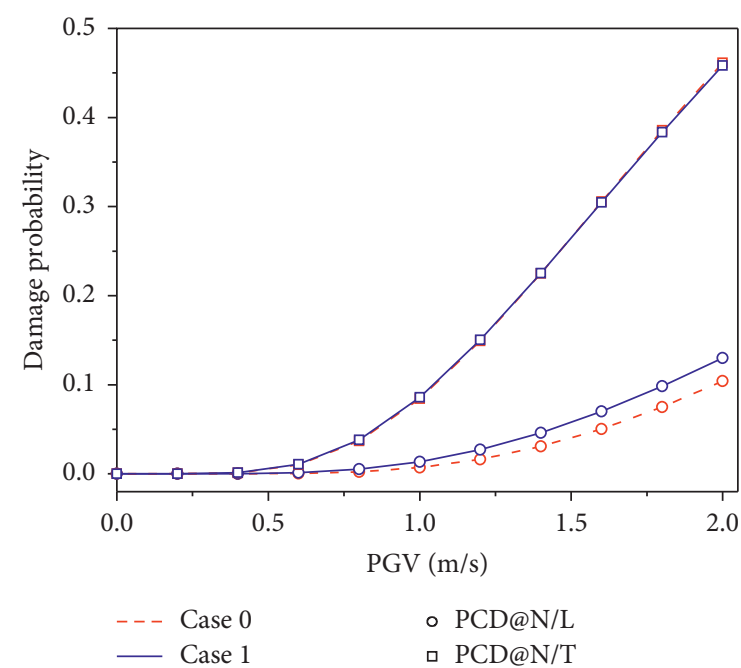

(b)

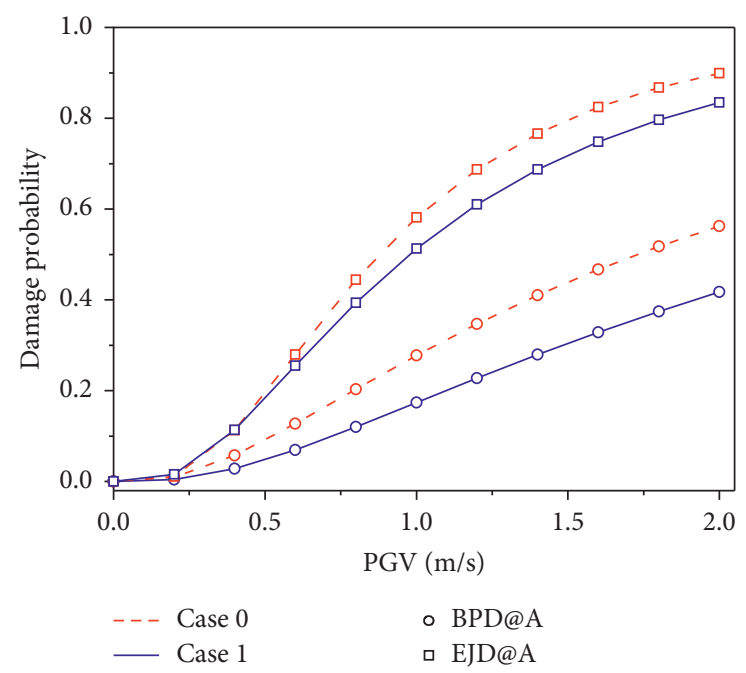

(c)

FIGURE 14: Influence of dampers on vulnerabilties of (a) bearing responses for DS2; (b) pylon responses for DS2, and (c) abutment and pounding responses.

initial walking. The displacement value $\Delta_{2}$ can be of $250 \%$ effective shear strain (ESS). The initial stiffness $K_{0}$ is calculated by MOTC [20]. Therefore, the coefficients can be calculated by the following sequence: $F_{d}$, $K_{0} \longrightarrow F_{\max } \longrightarrow \Delta_{1} \longrightarrow \Delta_{2}$. The built analytical relation of the LEB is shown in Figure 16(a), which can correctly capture mechanical behavior under earthquakes. A lognormal distribution [8] with a logarithmic standard deviation of 0.1 and a normal distribution with a $\mathrm{COV}=0.16 \mathrm{MPa}$ were used to model the randomness of friction coefficient and shear modulus, respectively. For their respective mean values, 0.2 and $1.2 \mathrm{MPa}$ were taken.

Figure 15(b) shows a cyclic loading experiment of LRB, which reveals that the degradation of bearings stiffness will occur with the increase of loading displacements. The elastic stiffness can reach uniformly 3 to 7 times the postyielding stiffness, according to the experimental results. The mechanical behavior of LRB can be modeled by a bilinear relation as seen in Figure 16(b).

The cable restrainers were modeled as nonlinear tensiononly elements characterized by an initial slack as shown in Figure 16(c). The parameters affecting the functionality of cable restrainers were the cable slack, length, and yield strength according to the research of Padgett and DesRoches [16]. The first two parameters were assumed to follow the uniform distributions, and the strength can be modeled by the lognormal distribution. An adopted range of cable stiffness values was from $3.0 \times 10^{5} \mathrm{kN} / \mathrm{m}$ to $5.0 \times 10^{5} \mathrm{kN} / \mathrm{m}$ uniformly.

The key parameters in analytical models of Figure 16 can be determined according to the structural design of the realistic bridge. The damage states of two restraint systems are listed in Table 6, in which ESS is used as the damage index. 

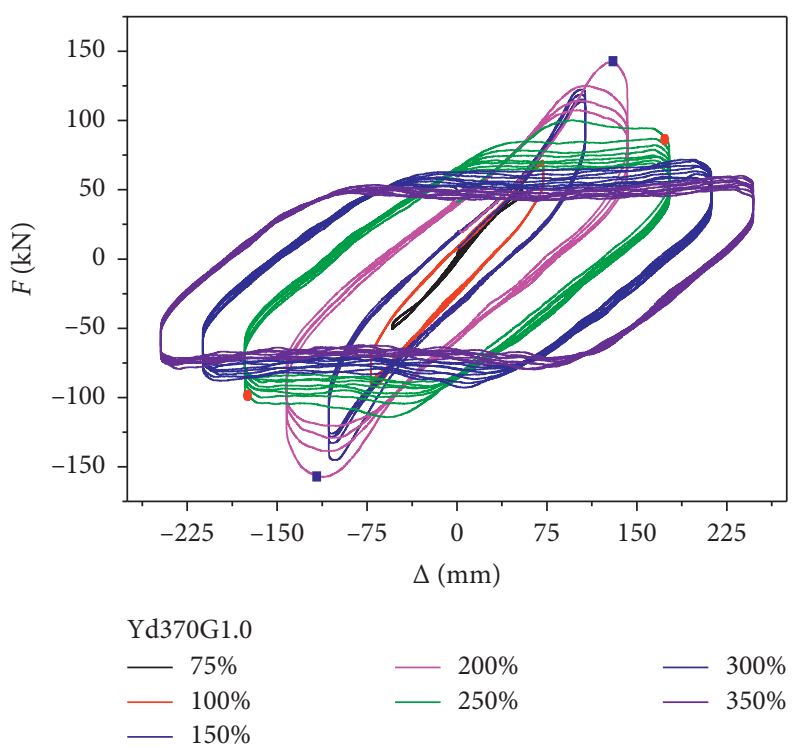

(a)

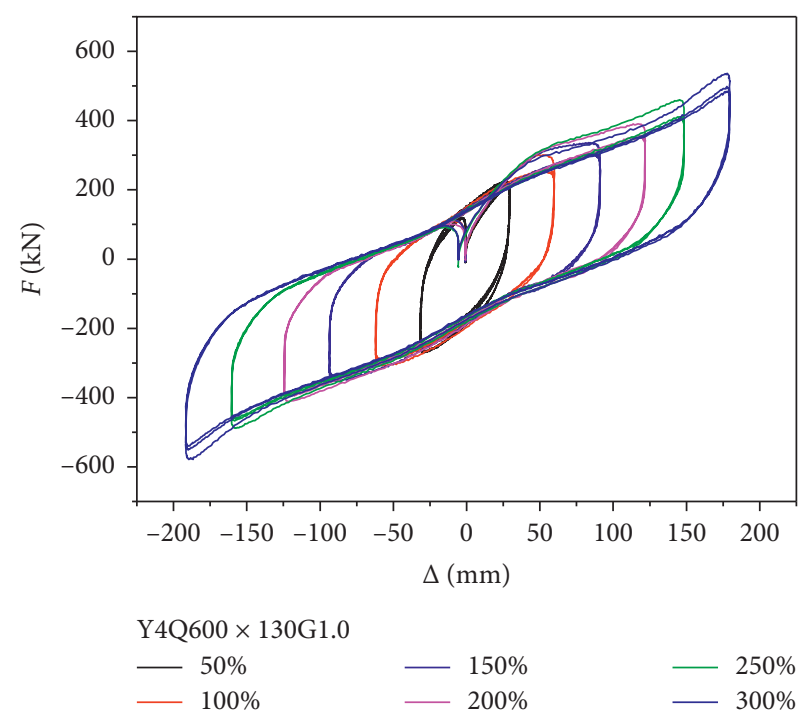

(b)

FIGURE 15: Experimental results of (a) LEB and (b) LRB.

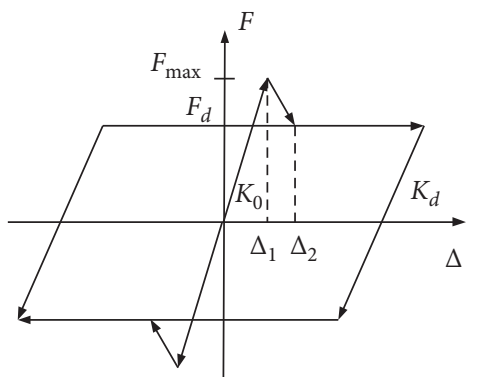

(a)

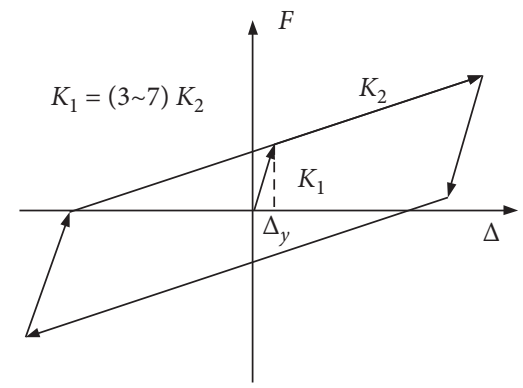

(b)

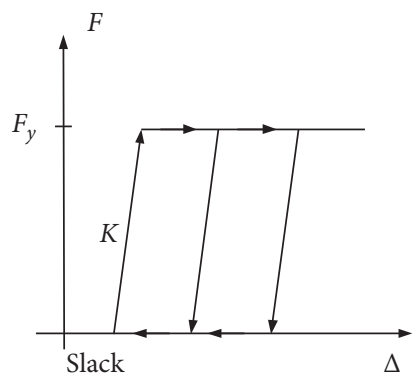

(c)

FIgURe 16: Analytical models of (a) LEB; (b) LRB; and (c) cable restrainers.

Figure 17 illustrates the probabilities of critical damage state occurrence sequences of the bridge components in Cases 1, 4, and 5 when PGV is $1.0 \mathrm{~m} / \mathrm{s}$, which is equal to E2 earthquake intensity in the seismic assessment reports. The component vulnerabilities of initial design (Case 0 ) were taken as the reference values, which were marked by different colored strips in Figure 17. The desirable sequence preferred Cases 4 or 5 for the approach bridges. The initial design of approach bridges resulted in unreasonable damage sequences. In the strategies pertaining to quasi-isolation and isolation systems, multiple tiers of seismic structural redundancy can be normally employed to prevent structural collapse during strong earthquake events. Tier 1 indicated that the bearings were weakly fused, which was evident in the high fragility of bearing sliding behaviors (ABD@A/L and ABD@C2/T). Another advantage was that the extensive damages of bearing would be reduced, when compared with the selfdamage of the pot bearings; Tier 2 indicated that the designed bearings had sufficient seat widths for adapting to the sliding of superstructures. However, the devices had a certain damage probability (EJD@A and SKD@C2) and dissipated a portion of the seismic energy when the displacement of the superstructures became larger than the allowable values of constraint devices; Tier 3 redundancy was designed as a potential plastic hinge in the substructures (CCD@C2), including a certain yielding of the backfill at the abutments (BPD@A). The response of the abutments in the transverse direction (PD@A/T) was slightly increased due to the pounding effect between the girders and shear keys caused by bearing sliding. The reasonable damage sequence of two restraint systems can be reflected through the corresponding damage probabilities of bearings, seismic measures, and substructures, respectively, as indicated by the red and green lines in Figure 17. Therefore, the rational sequence of critical limit state occurrences for the approach bridges is bearings $\longrightarrow$ expansion joints (or restrainer cables), shear keys $\longrightarrow$ columns, abutments.

4.3. Comprehensive Evaluation of Bridge System. Padgett and DesRoches [16] pointed out the necessity to derive the bridge system vulnerabilities when assessing retrofitted bridges, 
TABLE 6: Damage states of the quasi-isolation and isolation bearings (m).

\begin{tabular}{|c|c|c|c|c|c|}
\hline & & DS1 & DS2 & DS3 & DS4 \\
\hline Criteria & & $\begin{array}{l}\text { Initial slipping or } \\
\text { dissipation, } \\
75 \% \text { ESS }\end{array}$ & $\begin{array}{c}\text { Possible pounding; entering of } \\
\text { abutments } \\
\text { nonlinearity or shear key } \\
\text { degradation }\end{array}$ & $\begin{array}{c}\text { Complete damage of the } \\
\text { bearings, } 300 \%(250 \%) \\
\text { ESS }\end{array}$ & $\begin{array}{l}\text { Possible } \\
\text { unseating }\end{array}$ \\
\hline \multirow{2}{*}{$\begin{array}{l}\text { Quasi- } \\
\text { isolation }\end{array}$} & ABD@C/T & 0.071 & 0.162 & 0.285 & 0.57 \\
\hline & ABD@A/L & 0.053 & 0.095 & 0.213 & 0.75 \\
\hline \multirow{2}{*}{ Isolation } & ABD@C/T & 0.105 & 0.162 & 0.35 & 0.57 \\
\hline & ABD@A/L & 0.079 & 0.095 & 0.263 & 0.85 \\
\hline
\end{tabular}

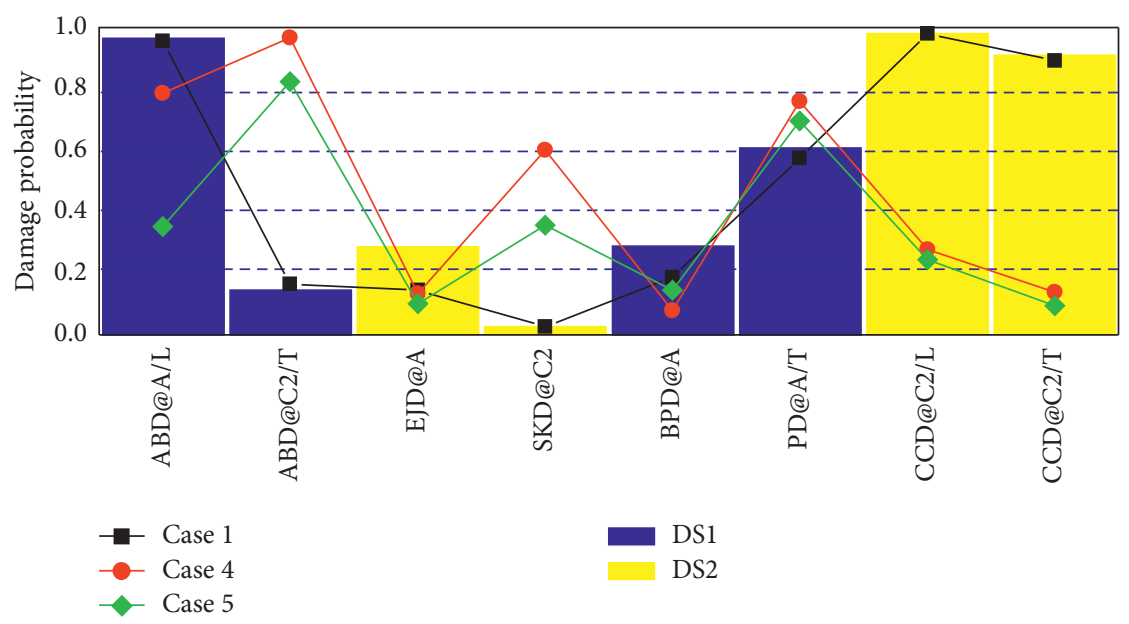

FIgURE 17: Probabilities of critical damage states occurrence sequences for the approach bridges when PGV is $1 \mathrm{~m} / \mathrm{s}$.

because different components may have a different response with a given retrofit measure. Also, Zhang and Huo [18] studied the optimal parameters of isolation bearings by deriving the intensity median value corresponding to system-level fragility function, which can effectively avoid the impacts of different isolation parameters on different components. As can be seen from Figures 14 and 17, the above analysis results were also very apparent in this study. For example, the longitudinal deck displacement was significantly reduced by using dampers yet increased the transverse demands of stiffening girder and pylons. The use of LEB or LRB reduced the demands placed on columns yet led to an increase of the transverse deformations of abutments, which was due to the use of shear keys limiting the excessive sliding displacement of bearings. Therefore, a comprehensive evaluation of retrofit strategies on bridges, particularly long-span suspension bridges that have multiple components, should be based on system-level fragility instead of component-level.

Taking the findings that no damages had occurred to the cable system and the definition of bearing damage states into account, the derivation of system-level fragility of the whole bridge depended on critical components including pylons, columns, bearings, and abutments. The fragility data by employing the absolutely serial and serial-parallel assumptions of bridge system are plotted in Figure 18 and compared to the system fragility obtained from the proposed composite damage state. The absolutely serial assumption generated serious bias for fragility curves and may result in misdirection if they were served as a design guide. The absolutely serial model overestimated the potential damage of the bridge system, since the fragility curve directly depended on the most vulnerable components. In other words, if the difference in location and performance of each component was neglected, then the seismic performance evaluation would be achieved by attaching equal importance to the strength of pylons, approach columns, and bearings. This method contradicted the philosophy of capacity design, in which the long-span structure can dissipate energy through a reasonable swinging of stiffening girder and the bearings were designed as fuse elements in the small-tomedium-span bridges. The serial-parallel model qualitatively incorporated the differences of components and was very sensitive to the seismic design of the structure as seen from the comparisons among the cases in Figure 18. The model distinguished the serial components and parallel components, yet still overestimated the bridge system-level fragility when bearings became the vulnerable components, especially for long-span bridges. This special situation, such as the serial assumption, may also lead to misunderstanding. Once the relative importance between the components was considered in the serial-composite model, the damage potential was clearly reduced within the range of earthquake intensity of interest based on the case studies. This also reflected the necessity of the classification idea of bridge components, which can be expressed by the numerical value 

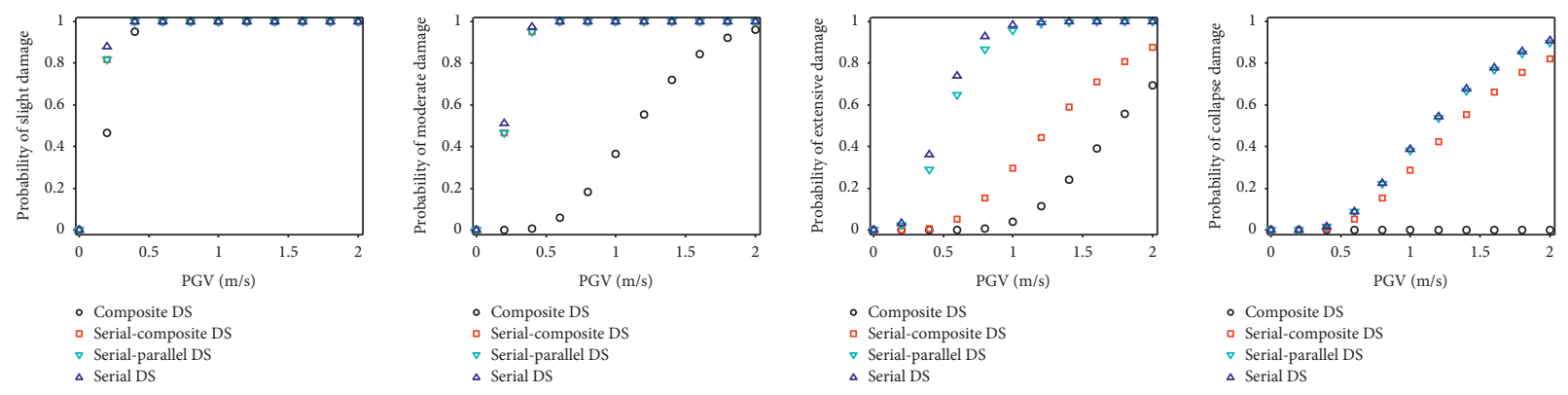

- Serial-composite DS

$\triangle$ Serial DS
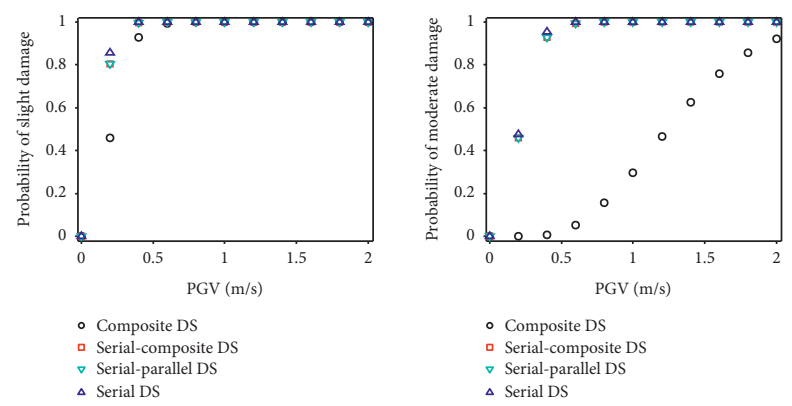

(a)

\section{- Composite DS
- Serial-composite DS \\ $\checkmark$ Serial-parallel DS}

$\triangle$ Serial DS

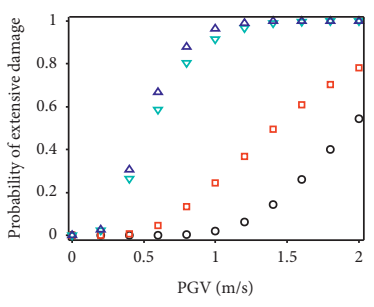

- Composite DS

Serial-composite DS

$\checkmark$ Serial-parallel DS

(b)

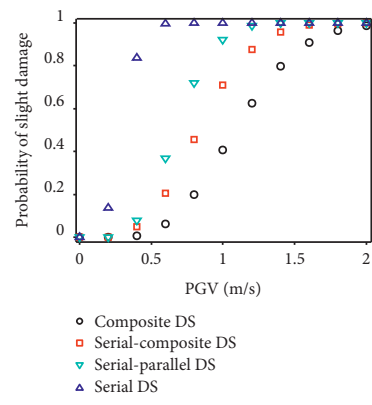

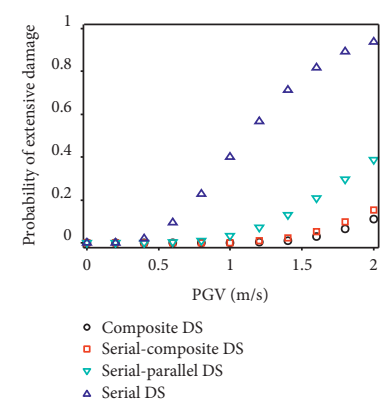

(c)
- Composite DS

- Serial-composite DS

$\checkmark$ Serial-parallel DS

$\triangle$ Serial DS
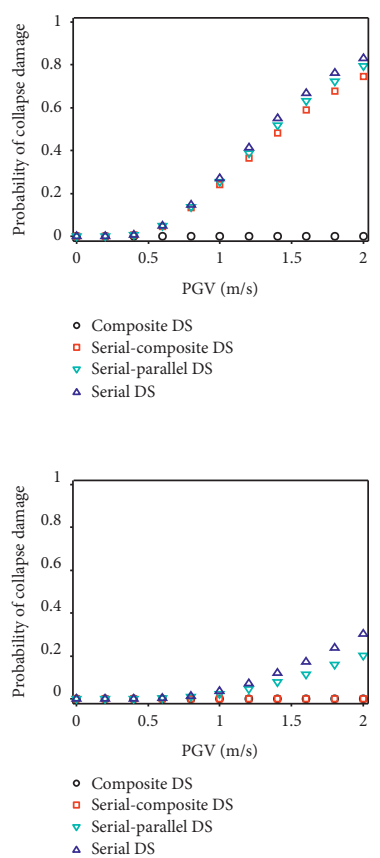

FIgure 18: System fragility of the original design (a) Case 0 and improved design including (b) Case 1 and (c) Case 5.

of system-level fragility. Therefore, the application of composite damage state (equation (4)) considering component difference was instead more appropriate than the aforementioned two models.

The damage probability distribution represented by black circles in Figure 18 can be obtained from the defined composite damage state (equation (5)), where the parameter $a$ is 0.6 . It was found that system fragility result was a more accurate assessment with further taking the relative importance between the main bridge and approach bridges into account. This is due to the principle that the seismic design performance objective of long-span bridges generally has no collapse for the main body structures and is necessarily open to emergency vehicle service. In addition, attention must be paid to the fact that the differences in repair cost and time of the main and approach bridges are significant when the same damage state is achieved. The results of composite damage state may match the performance objectives of the seismic design. In order to investigate the influence of improved strategies and structural relative importance on damage potential of bridges, the mean values of the fragility functions can be employed to evaluate the seismic design. The smooth fragility curves for the specific damage states can be fitted with the lognormal cumulative probability distribution function by employing the least-squares technique:

$$
P\left[D S>D S_{i} \mid P G V\right]=\Phi\left(\frac{\ln (p g v)-\lambda_{\mathrm{PGV}}}{\zeta_{\mathrm{PGV}}}\right),
$$

where $\lambda_{\mathrm{PGV}}$ and $\zeta_{\mathrm{PGV}}$ are the logarithmic mean and dispersion values of earthquake intensity (PGV) for a specified damage level. The larger mean values represent the smaller damage potential to reach the specified level.

Figure 19 indicates the mean values of earthquake intensity at the specific damage states, as a function of the improved strategies and parameter $a$. Each step of the retrofit measures would enhance the seismic performance of the overall bridge system at all levels. The improvement of the restraint system of the approach bridge played a critical role of the overall bridge system. For instance, the mean values of the earthquake intensity featured mutation of slopes along the measure direction, which reflected the 


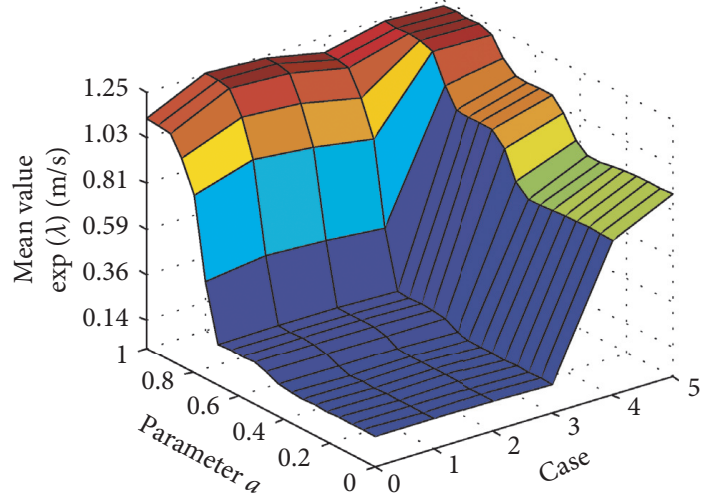

(a)

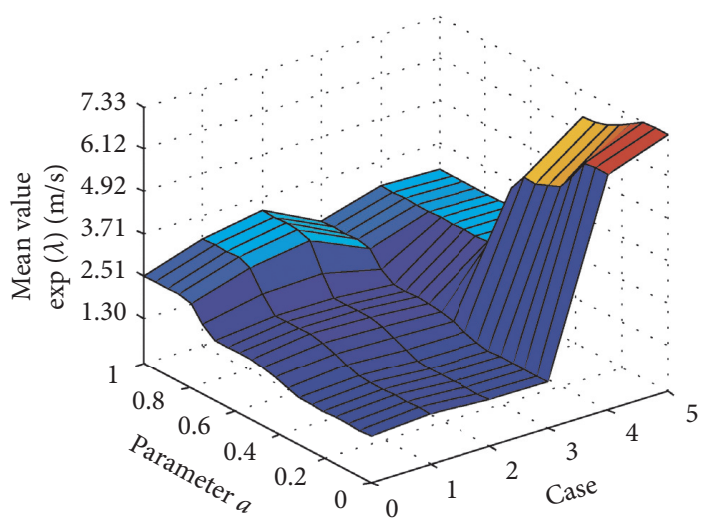

(c)

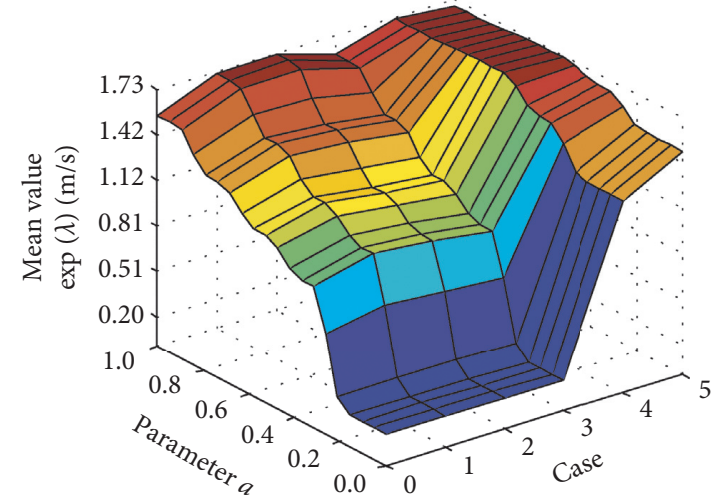

(b)

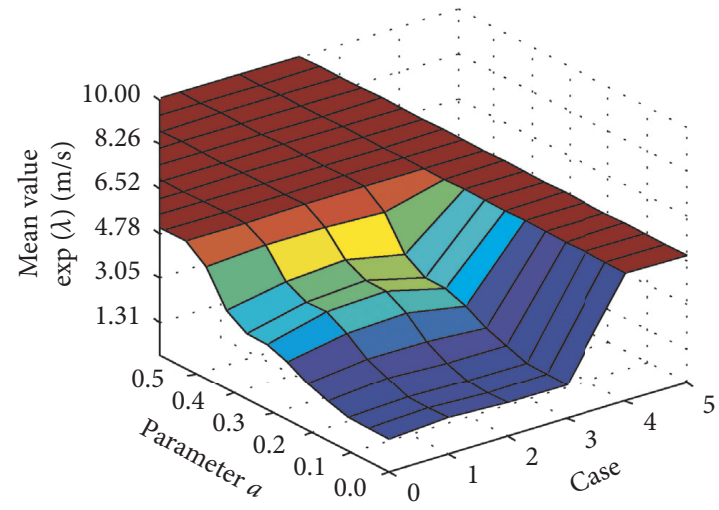

(d)

FIGURE 19: Influence of relative importance and improved designs on mean values of earthquake intensity for different damage states: (a) slight; (b) moderate; (c) extensive; (d) collapse.

fact that the effectiveness of improvement for the approach bridges was clearer than that of the main bridge. The fragility of the highway network would be underestimated if only the damage potential of the suspension span was adopted. Therefore, when the structures such as approach bridges, transition piers, and auxiliary piers were ignored, the damage identification and repair decisions would be misleading in the seismic evaluation of long-span bridges. Conversely, the damaging probability of the overall bridge system will be amplified regardless of the higher importance of the main bridge. When respect the fact that the importance of suspension span is higher than that of approach bridge in transportation networks, a parameter $a$ of $0.6-0.8$ may be a better choice in the present study.

The seismic fragility of conventionally designed bridges was mainly governed by the approach bridges at all damage levels. However, for the retrofitted bridges that possess reasonable seismic performance, different damage states were controlled by the earthquake demands of various structures, as shown by the trend of the curves along parameter $a$ in Case 4 and Case 5. The damaging potential of the overall bridge from the low-to-moderate limit states was dominated by the approach bridge. The primary reasons were the sliding of bearings and the transfer of limited forces from the girder to substructure by the damage of restriction devices of the approach bridges. The extensive damage was controlled by the displacement of stiffening girder of the main bridge, which inferred the effect of dampers will be conspicuous under strong earthquake shaking. At the same time, the overall long-span bridges with the reasonable seismic system will not collapse during a strong earthquake event and can meet emergency traffic service. It can be seen that the mean values of fragility functions developed by composite damage indices (equations (4) and (5)) are good indicators to evaluate seismic performance of long-span bridges and can be consistent with the established seismic performance objectives.

\section{Conclusions}

In the present study, a procedure for investigating the reasonable seismic performance of long-span suspension bridges was developed under the fragility function framework. The seismic performance of a long-span suspension bridge was examined and improved using the proposed procedure, from which the results revealed distinguishable conclusions as follows:

(1) The definition of damage states for bearings considered the interactions between the adjacent 
structures and self-damage to bearings, in accordance with the actual design and experimental conclusions. The damage states of pylons in terms of curvature ductility were defined by developing modal pushover analysis and idealized bilinear fitting methods in the equivalent pylon fiber models of the suspension bridge.

(2) When investigating the component fragility curves of the initial design, it was found that the large deck displacement of the suspension span was the most serious damage present, and a slight inelastic response may have occurred only in the pylons. Although the cable system was able to maintain elasticity under earthquakes, the saddles at the pylons were identified with a high-risk region indicating the damaging potential. For the approach bridges, the ductility mechanism did not realize a rational damage sequence. The columns were prone to collapse because of the application of fixed pot bearings, which in turn caused the damage to the bearings and abutments.

(3) The stepwise improved seismic designs were proposed in terms of the component fragility results of the initial design. Among the candidates, fluid viscous dampers were proven to be a good choice for long-span bridges based on the two attributes of displacement and force when the similar efficiency of displacement control was achieved. The restraint system had a critical effect on the seismic responses of the approach bridges. The quasi-isolation or isolation can achieve a reasonable seismic damage sequence of the approach bridges.

(4) The defined composite damage indices showed that the incorporate component classification concept and structural relative importance were necessary to derive a good indicator of performance evaluation, due to the fact that the damage indices were based on either an absolutely serial or serial-parallel system model may significantly overestimate the damage potential of the overall bridge system. The mean values of earthquake intensity at the specific damage states can serve as a function of the improved strategies and relative importance to further evaluate the overall seismic performance of the suspension bridge. It can be concluded that the damaging potential of the overall bridge from the low-to-moderate limit states was governed by the approach bridges in the retrofitted bridges with a favorable seismic performance, whereas the displacement demand of the suspension span dominated the fragility probability of the extensive damage.

\section{Data Availability}

The nature of the data is the analytical data of finite element models of the case bridge. The data used to support the findings of this study are available from the corresponding author upon request.

\section{Conflicts of Interest}

The authors declare that they have no conflicts of interest.

\section{Acknowledgments}

This work was supported by the Basic Research Service Project of Central-Level Public Welfare Research Institute (grant nos. 2016-9018 and 2019-0034) and Science and Technology Project of Communications' Construction in Western China, MOC (grant no. 2009318223094).

\section{References}

[1] L. W. David, A. Kartoum, K. Chang, and I. Roy, "Suspension report seismic performance and design considerations of long span suspension bridges," Report CSMIP/00-03, California Department of Conservation Division of Mines And Geology Office of Strong Motion Studies, Sacramento, CA, USA, 2000.

[2] S.-G. Gwon and D.-H. Choi, "Improved continuum model for free vibration analysis of suspension bridges," Journal of Engineering Mechanics, vol. 143, no. 7, Article ID 04017038, 2017.

[3] S. Arzoumanidis, A. Shama, and F. Ostadan, "Performancebased seismic analysis and design of suspension bridges," Earthquake Engineering and Structural Dynamics, vol. 34, no. 4-5, pp. 349-367, 2005.

[4] L. Sgambi, E. Garavaglia, N. Basso, and F. Bontempi, "Monte Carlo simulation for seismic analysis of a long span suspension bridge," Engineering Structures, vol. 78, pp. 100-111, 2014.

[5] D. Karmakar, S. Ray-Chaudhuri, and M. Shinozuka, "Finite element model development, validation and probabilistic seismic performance evaluation of Vincent Thomas suspension bridge," Structure and Infrastructure Engineering, vol. 11, no. 2, pp. 223-237, 2015.

[6] W.-F. Chen and L. Duan, Bridge Engineering Handbook: Seismic Design, CRC Press, Boca Raton, FL, USA, 2nd edition, 2014.

[7] E. Choi, "Seismic analysis and retrofit of mid-america bridges," Doctoral thesis, Georgia Institute of Technology, Atlanta, GA, USA, 2002.

[8] B. G. Nielson and R. DesRoches, "Seismic fragility methodology for highway bridges using a component level approach," Earthquake Engineering \& Structural Dynamics, vol. 36, no. 6, pp. 823-839, 2007.

[9] K. N. Ramanathan, "Next generation seismic fragility curves for california bridges incorporating the evolution in seismic design," Doctoral thesis, Georgia Institute of Technology, Atlanta, GA, USA, 2012.

[10] Ö Avşar, A. Yakut, and A. Caner, "Analytical fragility curves for ordinary highway bridges in Turkey," Earthquake Spectra, vol. 27, no. 4, pp. 971-996, 2011.

[11] S. P. Stefanidou and A. J. Kappos, "Methodology for the development of bridge-specific fragility curves," Earthquake Engineering \& Structural Dynamics, vol. 46, no. 1, pp. 73-93, 2016.

[12] B. Borzi, P. Ceresa, P. Franchin, F. Noto, G. M. Calvi, and P. E. Pinto, "Seismic vulnerability of the Italian roadway bridge stock," Earthquake Spectra, vol. 31, no. 4, pp. 2137-2161, 2015.

[13] W. T. Barnawi and S. J. Dyke, "Seismic fragility relationships of a cable-stayed bridge equipped with response modification 
systems," Journal of Bridge Engineering, vol. 19, no. 8, Article ID A4013003, 2014.

[14] J. Zhong, Y. Pang, J. Jong-Su, J.-S. Jeon, R. DesRoches, and W. Yuan, "Seismic fragility assessment of long-span cablestayed bridges in China," Advances in Structural Engineering, vol. 19, no. 11, pp. 1797-1812, 2016.

[15] J. Zhong, Z. Hu, W. Yuan, and L. Chen, "System-based probabilistic optimization of fluid viscous dampers equipped in cable-stayed bridges," Advances in Structural Engineering, vol. 21, no. 12, pp. 1815-1825, 2018.

[16] J. E. Padgett and R. DesRoches, "Methodology for the development of analytical fragility curves for retrofitted bridges fitted bridges," Earthquake Engineering \& Structural Dynamics, vol. 37, no. 8, pp. 1157-1174, 2008.

[17] Y. Xie and J. Zhang, "Optimal design of seismic protective devices for highway bridges using performance-based methodology and multiobjective genetic optimization," Journal of Bridge Engineering, vol. 22, no. 3, Article ID 04016129, 2017.

[18] J. Zhang and Y. Huo, "Evaluating effectiveness and optimum design of isolation devices for highway bridges using the fragility function method," Engineering Structures, vol. 31, no. 8, pp. 1648-1660, 2009.

[19] F. McKenna, M. H. Scott, and G. L. Fenves, "Nonlinear finiteelement analysis software architecture using object composition," Journal of Computing in Civil Engineering, vol. 24, no. 1, pp. 95-107, 2010.

[20] MOTC, "Guidelines for seismic design of highway bridges," China Ministry of Transportation and Communications Press, Beijing, China, JTG/T B02-01-2008, 2008.

[21] A. D. Kiureghian and J. L. Sackman, "Tangent geometric stiffness of inclined cables under self-weight," Journal of Structural Engineering, vol. 131, no. 6, pp. 941-945, 2005.

[22] J. S. Steelman, E. T. Filipov, L. A. Fahnestock et al., "Experimental behavior of steel fixed bearings and implications for seismic bridge response," Journal of Bridge Engineering, vol. 19, no. 8, Article ID A4014007, 2014.

[23] B. Madani, F. Behnamfar, and H. Tajmir Riahi, "Dynamic response of structures subjected to pounding and structuresoil-structure interaction," Soil Dynamics and Earthquake Engineering, vol. 78, pp. 46-60, 2015.

[24] L. Xu and J. Li, "Design and experimental investigation of a new type sliding retainer and its efficacy in seismic fortification," Engineering Mechanics, vol. 33, no. 2, pp. 111-118, 2016, in Chinese.

[25] Caltrans, Caltrans Seismic Design Criteria, California Department of Transportation., Sacramento, CA, USA, 2013.

[26] A. Shamsabadi, K. M. Rollins, and M. Kapuskar, "Nonlinear soil-abutment-bridge structure interaction for seismic performance-based design," Journal of Geotechnical and Geoenvironmental Engineering, vol. 133, no. 6, pp. 707-720, 2007.

[27] X. Li, Z. Sun, D. Wang, and Y. Shi, "Longitudinal seismic pounding effect of bridges abutment and backfilling damage," Journal of Chang'an University, vol. 35, no. 4, pp. 76-82, 2015, in Chinese.

[28] MOTC, "Specification for design of highway suspension bridge," China Ministry of Transportation and Communications Press, Beijing, China, JTG/T D65-05-2015, 2015.

[29] A. Shafieezadeh, K. Ramanathan, J. E. Padgett, and R. DesRoches, "Fractional order intensity measures for probabilistic seismic demand modeling applied to highway bridges," Earthquake Engineering \& Structural Dynamics, vol. 41, no. 3, pp. 391-409, 2012.
[30] J. E. Padgett, B. G. Nielson, and R. DesRoches, "Selection of optimal intensity measures in probabilistic seismic demand models of highway bridge portfolios," Earthquake Engineering \& Structural Dynamics, vol. 37, no. 5, pp. 711-725, 2008.

[31] K. R. Mackie and B. Stojadinovic, "Fragility basis for california highway overpass bridge seismic decision making," PEER Report 2005/02, Pacific Earthquake Engineering Research Center, University of California Berkeley, Berkeley, CA, USA, 2005.

[32] J. Li, T. Peng, Ji Lin, L. Zhou, and YuL. Deng, Seismic Design of Multi-Pylon Multi-Span Suspension Bridge, China Communications Press, Beijing, China, 2013, in Chinese.

[33] L. Chen, W. Zhuang, H. Zhao, and Z. Wan, "Report on Highways' Damage in the Wenchuan Earthquake-Bridge, China Communications Press, Beijing, China, 2012, in Chinese.

[34] G. Wu, K. Wang, G. Lu, and P. Zhang, "An experimental investigation of unbonded laminated elastomeric bearings and the seismic evaluations of highway bridges with tested bearing components," Shock and Vibration, vol. 2018, Article ID 8439321, 18 pages, 2018. 